Louisiana State University

LSU Digital Commons

\title{
Spaced-retrieval effects on name-face recognition in older adults with probable Alzheimer's disease
}

Karri Sikes Hawley

Louisiana State University and Agricultural and Mechanical College

Follow this and additional works at: https://digitalcommons.Isu.edu/gradschool_theses

Part of the Psychology Commons

\section{Recommended Citation}

Hawley, Karri Sikes, "Spaced-retrieval effects on name-face recognition in older adults with probable Alzheimer's disease" (2002). LSU Master's Theses. 4245.

https://digitalcommons.Isu.edu/gradschool_theses/4245

This Thesis is brought to you for free and open access by the Graduate School at LSU Digital Commons. It has been accepted for inclusion in LSU Master's Theses by an authorized graduate school editor of LSU Digital Commons. For more information, please contact gradetd@lsu.edu. 


\title{
SPACED-RETRIEVAL EFFECTS ON NAME-FACE RECOGNITION IN OLDER ADULTS WITH PROBABLE ALZHEIMER'S DISEASE
}

\author{
A Thesis, \\ Submitted to the Graduate Faculty of the \\ Louisiana State University and \\ Agricultural and Mechanical College \\ in the partial fulfillment of the \\ requirements for the degree of \\ Master of Arts \\ In
}

The Department of Psychology

by

Karri Sikes Hawley

B. S., Georgia Southern University, 1993

M. Ed., The University of North Florida, 1996

May 2002 


\section{TABLE OF CONTENTS}

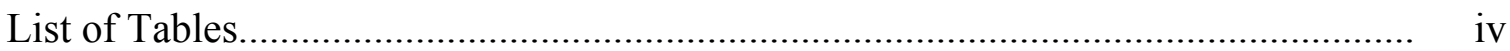

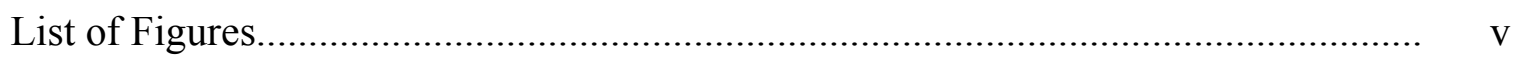

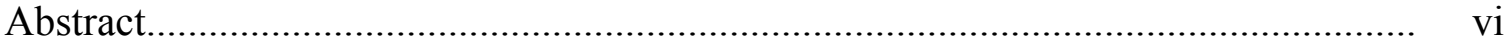

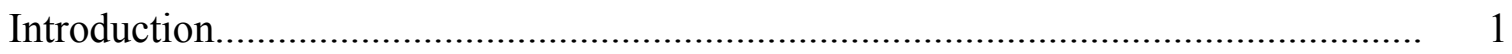

Review of Literature.......................................................................................

Adult Dementia: Definitions and Diagnostic Issues................................................ 3

Background Information on AD................................................................... 5

Prevalence of AD ............................................................................................. 7

Mental and Behavioral Deficits in AD Patients...................................................... 9

Cognitive Deficits.......................................................................... 15

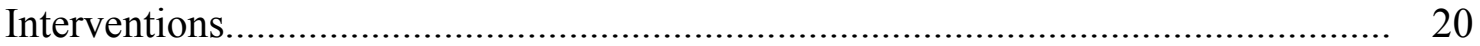

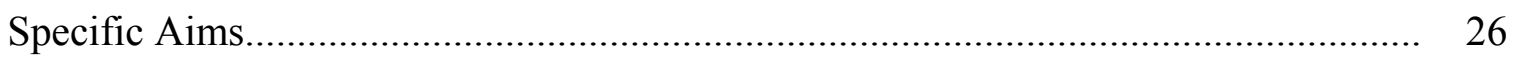

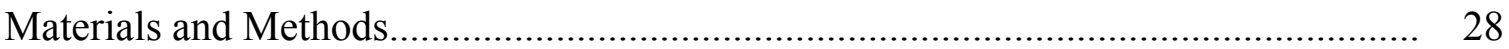

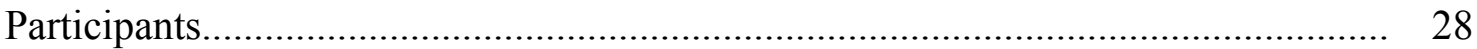

Individual Difference Measures......................................................................... 28

Baseline Measures of Memory............................................................................ 34

Summary of Spaced-Retrieval Training Program............................................... 35

Explicit Memory for the Trained Object............................................................. 37

Live Person Transfer Task .............................................................................. 38

Final Face Recognition Task....................................................................... 39

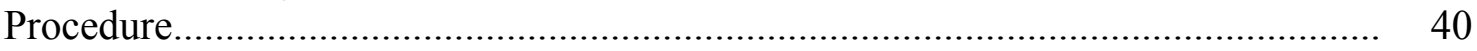

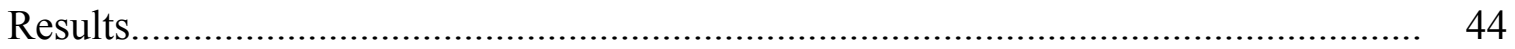

Baseline Measures of Memory.......................................................................... 44

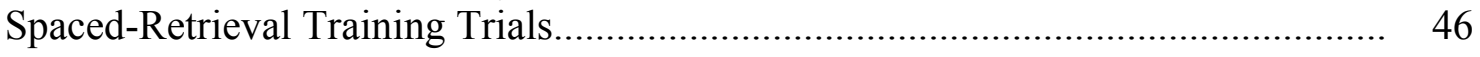

Explicit Memory for the Target Person............................................................... 53

Final Face Recognition Task ............................................................................. 58

Training Schedule Findings......................................................................... $\quad 58$

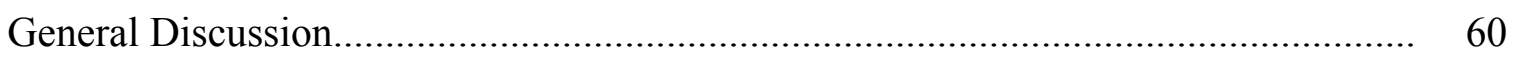

Spaced-Retrieval Effects.................................................................................. 60

Transferring Spaced-Retrieval Training Association to a Live Person...................... 61

Spaced-Retrieval Training Schedule............................................................. 62

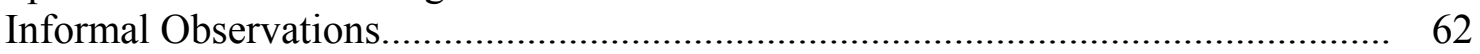




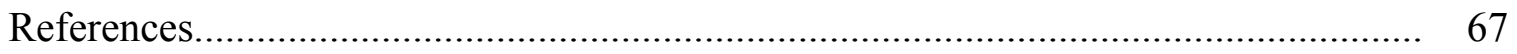

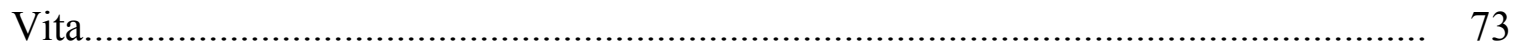




\section{LIST OF TABLES}

1. Common Disorders Associated with Dementia Syndrome................................. 4

2. Diagnostic Criteria for Dementia of the Alzheimer's Type................................. 8

3. Functional Assessment Stages in Normal Aging and Alzheimer's Disease....... 10

4. Typical Pattern of Progression of Language Disorder in Alzheimer's Disease.. 18

5. Summary of Demographic and Health Characteristics...................................... 29

6. Summary of Health and Social Activity Characteristics................................... 30

7. List of Individual Difference Measures Given to Participants............................ 31

8. Summary of Individual Difference Measures.................................................... 33

9. Summary of Experimental Procedure ......................................................... 42

10. Summary of Nametag Task.................................................................... 45

11. Summary of Spaced-Retrieval Task Performance............................................. 47

12. Proportion of Partially Correct Failed Trials................................................... 48

13a. Transfer Task Performance for Alternate Day S-R Schedule............................. 49

13b. Transfer Task Performance for Consecutive Day S-R Schedule........................ 49

14a. Summary of Immediate Recall Task for Alternate Day S-R Schedule............... 54

14b. Summary of Immediate Recall Task for Consecutive Day S-R Schedule.......... 54

15a. Summary of Delayed Recall Task for Alternate Day S-R Schedule................... 56

15b. Summary of Delayed Recall Task for Consecutive Day S-R Schedule.............. 56

16a. Summary of Final Delayed Recall Task for Alternate Day S-R Schedule......... 57

16b. Summary of Final Delayed Recall Task for Consecutive Day S-R Schedule.... 57

17. Summary of Final Face Recognition Task................................................... 59 


\section{LIST OF FIGURES}

1. Prevalence of Alzheimer's Disease by Age Group........................................ 1 


\begin{abstract}
Six older adults with probable Alzheimer's disease (AD) were trained to recall a nameface association using the spaced-retrieval method. We administered six training sessions over a two-week period. On each trial, participants selected a target photograph and stated the target name, from eight other photographs, at increasingly longer retention intervals. Results yielded a positive effect of spaced-retrieval training for name-face recognition. All participants were able to select the target photograph and state the target's name for longer periods of time within and across training sessions. A live person transfer task was administered to determine whether the name-face association, trained by spaced-retrieval, would transfer to a live person. The live person target was the same target that was used in the spaced-retrieval training sessions. Half of the subjects were able to call the live person by the correct name. These data provide initial evidence that spaced-retrieval training can aid older adults with probable $\mathrm{AD}$ in recall of a name-face association and transfer that association to an actual person.
\end{abstract}




\section{INTRODUCTION}

Older adults comprise the fastest growing segment of the population in the U.S. today. From 1900-1994, the elderly population, defined as those Americans age 65 and older, increased 11-fold compared to those Americans under age 65 who only increased in number by 3-fold (U.S. Bureau of the Census, 1996). The elderly population is expected to substantially increase from $2010-2030$ as baby boomers begin to reach 65 years of age.

Currently, elderly adults make up $13 \%$ of the U.S. population. This number is expected to reach $18 \%$ by 2025 . The oldest old population (those over 85 years of age) is predicted to more than double in number from 1994 to 2020, reaching 7 million by 2020 (U.S. Bureau of the Census, 1996). These demographic trends are of great concern to social planners and other professionals in senior service fields. One pressing concern is that as many as half of all people over the age of 85 are believed to have dementia. Figure 1 shows the prevalence of $\mathrm{AD}$ according to age group. Close to $50 \%$ of all patients with Alzheimer's disease (AD) are over the age of 85 as can be seen in Figure 1 (Alzheimer's Association, 1998).

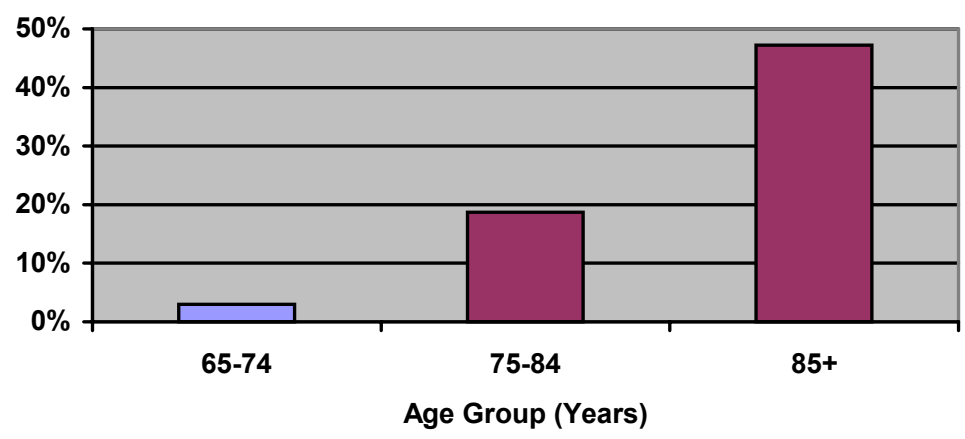

Figure 1: Prevalence of Alzheimer's Disease By Age Group

Data taken from: The Alzheimer's Association, 1998. 
As the number of persons with adult dementia increases, the number of persons caring for these individuals will also increase. There are currently over 22 million households in the U.S. providing care for older adults. Dementia related disease exists in more than $20 \%$ of these cases (Ory, Hoffman, Yee, Tennstedt, \& Schulz, 1999). That calculates to more than 5 million U.S. households caring for a dementia patient. A National Institute on Aging (NIA) (1999) Alzheimer's disease report estimated the cost of caring for an AD patient in terms of mild, moderate and severe dementia. The annual costs associated with the care of a mild dementia patient were $\$ 18,408$, the moderate dementia patient $\$ 30,096$ and the severe dementia patient $\$ 36,132$. The average lifetime cost of caring for an $\mathrm{AD}$ patient is estimated to be $\$ 174,000$ (NIA, 1999). Alzheimer's disease is certain to remain a prominent public health issue as our country continues to age and the number of persons affected by AD increases. As a result, research in the area of interventions for AD is important to improve the quality of life, not only for persons suffering with AD, but those who care for them.

This paper is organized as follows. In the first section, definitions and diagnostic issues in adult dementia are discussed. In the second section, specific background information on Alzheimer's disease is discussed. In the third section, mental and behavioral deficits present in Alzheimer's disease patients are addressed. The fourth section focuses on cognitive deficits associated with Alzheimer's disease, with emphasis on memory and interventions to improve retention. In the last section, specific aims of the present research are presented, followed by research methods, results, and the general discussion. 


\section{REVIEW OF LITERATURE}

\section{Adult Dementia: Definitions and Diagnostic Issues}

Raskind and Peskind (1992) define dementia as a syndrome that includes a group of signs and symptoms that cluster together. Adult dementia can be produced by many different underlying, etiologically distinct physical conditions. In other words, the dementia syndrome can be produced by multiple disorders. The DSM-IV describes the development of multiple cognitive deficits, which must include memory impairment as the key defining condition in dementia. Table 1 outlines the most common disorders and symptoms associated with the dementia syndrome (Raskind \& Peskind 1992).

Although the symptoms of dementia are easily observed, diagnosis, especially in the early stages, can prove difficult for clinicians. Behavioral problems are typically the presenting symptoms that prompt an evaluation for dementia (Jarvik, 1980). The subjective nature of these types of symptoms can make it difficult to determine exactly what factors are responsible. Dementia is a major feature of Alzheimer's disease, but other conditions that cause dementia must be ruled out first before a provisional diagnosis of $\mathrm{AD}$ would be warranted. For example, depression in particular can prove difficult to distinguish from dementia, especially in the early stages (Raskind \& Peskind, 1992). In addition, there are multiple dementia syndromes as well as other common reversible and irreversible causes of dementia that should be considered on initial assessment. The reversible conditions that can cause the dementia syndrome include acute confusional states, drug effects, malnutrition, depression, psychological and social stresses, paranoid disorders and intracranial lesions [for further discussion of these conditions see Jarvik, 1980]. 


\section{Table 1: Common Disorders Associated with Dementia Syndrome}

Type

Alzheimer's disease

Multi-infarct dementia

Cruetzfeldt-Jakob disease

Dementia with Lewy bodies ${ }^{1}$

Parkinson's disease

Pick's disease

Huntington's disease
Presenting symptoms

Insidious onset, progressive deteriorating course. In early stages; subtle difficulties in memory, memory loss more marked for recent events, repetition in conversation, disorientation in unfamiliar settings. Definitive diagnosis only after autopsy.

A vascular dementia, abrupt onset, stepwise deterioration, focal neurologic signs and symptoms.

Rare, fatal brain disorder likely due to a virus. Memory declines, loss of coordination, pronounced mental deterioration, involuntary muscle spasms, blindness, weakness in arms and legs, coma. Definitive diagnosis only after autopsy.

Widespread Lewy bodies in CNS. Dementia, variation in cognition with extreme fluctuation in alertness, visual hallucinations. Episodes of confusion and depression more frequent than in AD.

Loss of motor ability, memory impairment, slowness of thinking, preserved language ability.

Rare dementing disorder, clinically similar to AD, although the neurochemistry and neuropathology is quite different from $\mathrm{AD}$. Changes in personality, orientation.

Begins in midlife, intellectual decline, irregular and involuntary movement of limbs/facial muscles. Personality change, memory declines, slurred speech, impaired judgment, psychiatric problems. Genetic marker identified on chromosome 4.

Note. Table adapted from Cherry and Plauche, 1996.

${ }^{1}$ Information taken from Lopez et al., 2000 
Although there is currently no cure for $\mathrm{AD}$, early detection of the illness is beneficial on many levels. The advantages for the patient and family include getting answers to questions and gaining understanding that the illness is responsible for personality and cognitive changes. Early detection also allows for better planning for the future. Early evaluation permits the clinician to create a more specific treatment plan and better predict the course of the illness. Society benefits from early diagnosis of $\mathrm{AD}$ through cost savings brought about by the delayed institutionalization of the patient, a decrease in the number of driving accidents and a larger population for AD research (Doraiswamy, Stefferns, Pitchumani, \& Tabrizi, 1998).

\section{Background Information on AD}

The first physician to recognize what is known today as Alzheimer's disease was Aretaeus of Cappadocia in the $2^{\text {nd }}$ Century AD. Through the centuries, other physicians speculated on the nature of the deterioration of mental faculties in old age in some cases. By the early 1900's, the key neurological features of Alzheimer's disease had been determined. The three key features included: the description of senile plaques by Redlich (1892), neurofibrillary tangles by Alzheimer (1907), and granulovacuolar degeneration by Simchowitz (1910). Kraeplin gave the name Alzheimer's disease in honor of his pupil and key contributor, the German physician, Alois Alzheimer [for further discussion see Cherry \& Plauche, 1996, and Reisberg, Ferris, deLeon, Crook, \& Hayes, 1987].

A central feature of $\mathrm{AD}$ is the damage and destruction of neurons in the brain. There are two primary approaches to understanding the specific nature of the damage to neurons. The first is represented by biochemical studies that look at neuritic plaques and neurofibrillary tangles. The second approach is represented by molecular genetic studies, which look at 
chromosome 21, 14, and 1 (Peskind, 1996). These two approaches are discussed more fully next.

Alois Alzheimer described another physical component of $\mathrm{AD}$, the neuritic plaque, in his original description of the disease (Gruetzner, 1992). These plaques are normally found in the brain but are found in significantly higher amounts in the brains of AD patients. Those patients most severely impaired by $\mathrm{AD}$ have a higher prevalence of plaques in their brains. Plaques accumulate in the areas of the brain that are most effected by AD. The presence of plaques in the brain may be a better predictor of $\mathrm{AD}$ than the neurofibrillary tangles (Greutzner, 1992). The main component of the neuritic plaque is a protein B-Amyloid. Whether the B-Amyloid concentration is causing the neuronal damage or just a consequence of such damage is a central debate among researchers (Peskind, 1996).

Neurofibrillary tangles in the brain have been identified as a symptom of AD since the 1900's when Alois Alzheimer first described the condition. Gruetzner (1992) defines neurofibrillary tangles as "bundles of ordinary brain filaments that have become badly twisted (p. 210)." Filaments when viewed under a microscope appear hair-like. The presence of filaments in the brain is normal. When the filaments change and become twisted, they are considered abnormal. These tangles are found in the areas of the brain that affect memory and behavior. The severity of memory impairment and behavioral disturbances may be directly related to the amount of tangles found in the corresponding area of the brain (Gruetzner, 1992).

Genetic studies have found that mutations on chromosomes 21,14 and 1 are found in a rare form of $\mathrm{AD}$. Families with this early-onset of autosomal dominant $\mathrm{AD}$ account for only a very small percentage of AD cases. Scientists remain hopeful that understanding these 
genes will help our understanding of the more prevalent, non-inherited types of AD (Peskind, 1996).

\section{Prevalence of AD}

Currently, 5\% of the world's population suffers with Alzheimer's disease (Henderson, 1998). There are an estimated 18 million cases of AD worldwide (Henderson, 1998) and 4 million cases in the United States alone (NIA, 1999). Each year 360,000 new cases will be diagnosed. By 2020 there will be 30 million cases throughout the world (Henderson, 1998). In the U.S., it has been estimated that 14 million Americans will have the diagnosis by the year 2050 (NIA, 1999). The increasing prevalence of Alzheimer's disease has made the illness an important public health issue. Dementia patients make up a large part of the nursing home population. The estimates range from $50 \%$ to $80 \%$ of all nursing home residents suffer with Dementia (Hendrie, 1997). The average cost of nursing home care ranges from $\$ 42,000-\$ 70,000$ a year (NIA, 1999). The patient pays for approximately half the cost and the remainder is funded mostly by state and federal sources (Holden, 1987).

$\mathrm{AD}$ is a major economic burden on U.S. society. $\mathrm{AD}$ is the third most costly disease to treat with estimated annual costs reaching \$100 billion (Ernst \& Hay, 1994). Medicare pays for 90 days in a nursing home. The patients are then responsible until their financial resources are exhausted. At this point Medicaid pays the full amount (Holden, 1987). Close to two-thirds of all Medicare enrollees who had a diagnosis of AD or dementia reside in a long-term care facility (Eppig \& Poisal, 1996). Managed Medicare total costs per year for patients with dementia were 1.5 times higher than for patients without dementia. Seventy five percent of the higher costs were linked to inpatient expenses (Gutterman, Markowitz, Lewis, \& Fillit, 1999). 
In addition to the costs to care for $\mathrm{AD}$ patients there are also research expenses. The amount the federal government plans to spend on research in the area in 1999 is 400 million dollars (Alzheimer's Association, 1998). This number has drastically increased over the last 25 years when funding in 1976 reached about 4 million dollars (Holden, 1987).

As noted previously, Alzheimer's disease has commonalties with several other disorders. The uniqueness of Alzheimer's disease is best addressed by examining the DSMIV criteria. Table 2 contains the DSM-IV criteria for dementia of the Alzheimer's type (American Psychiatric Association, 1994).

Table 2: Diagnostic Criteria for Dementia of the Alzheimer's Type

DSM IV Criteria

A. The development of multiple cognitive deficits, including both:

1. Memory Impairment

2. One or more of the following cognitive disturbances:

a. aphasia

b. apraxia

c. agnosia

d. disturbance, in executive functioning

B. Cognitive deficits cause significant impairment in social or occupational functioning and represent a significant decline from a previous level of functioning.

C. Gradual onset and continuing cognitive decline

D. Cognitive deficits are not due to any of the following:

1. other central nervous system conditions

2. systemic conditions that are known to cause dementia

3. substance-induced conditions

E. The deficits do not occur exclusively during the course of a delirium

F. The disturbance is not better accounted for by another Axis I disorder

Note. Table adapted from Diagnostic and Statistical Manual of Mental Disorders (American Psychiatric Association, 1994). 
Dementia involves progressive decline in both cognitive abilities and daily functioning such as activities of daily living, communication, and social activities. In recent years, staging systems have been developed to monitor the gradual progression of deterioration (Cohen-Mansfield et al., 1996). The dementia patient can be assessed and placed appropriately along the staging continuum. Staging benefits future research in multiple ways. First, staging the natural course of dementia allows baseline information to be collected and to compare different samples of population and infer appropriate conclusions. Staging also helps the clinician to predict the course of the disease. Finally, utilization of staging systems may also prove useful in development of future societal policies (Reisberg et al., 1987). Table 3 contains the functional assessment stages in normal aging and AD.

\section{Mental and Behavioral Deficits in AD Patients}

Mental and behavioral disturbances are a central feature in dementia. Most all patients will exhibit these types of behavior at some point in their illness, which are often the most challenging symptoms to address. The Cache County, Utah study on memory in aging provided the first U.S. estimates on the population prevalence of behavioral and mental disturbances in individuals with dementia (Lyketsos et al., 2000). All participants were screened for dementia and underwent extensive neuropsychiatric examinations. Participants were evaluated using the Neuropsychiatric Inventory (Cummings et al., 1994). The study found behavioral and mental disturbance in $70-80 \%$ of all dementia cases (Lyketsos et al., 2000). In nursing homes $65 \%$ of dementia patients exhibit behavioral symptoms and these symptoms are often the cause of nursing home placement (Neistein \& Siegal, 1996). Behavioral and mental symptoms tend to occur in later stages as previous sections mentioned. Often behavioral disturbances are a result of an underlying mental condition. 
Table 3: Functional Assessment Stages in Normal Aging and Alzheimer's Disease

Global Deterioration

Scale Stage

1. No cognitive

decline

2. Very mild cognitive decline

3. Mild cognitive decline

4. Moderate cognitive decline

5. Moderately severe cognitive decline

6. Severe cognitive decline

7. Very severe cognitive decline
Clinical Diagnosis
Functional

Assessment

Characteristics
Normal

Normal for Age

Borderline

impairment

Mild AD

Moderate AD

Moderately

severe AD

Severe AD
No functional

decrement.

Complains of forgetting location of objects.

Decrease in functioning in demanding work settings; difficulty in new locations.

Decreased ability to perform tasks. (complex tasks)

Requires assistance in clothing; may require coaxing to bathe.

Requires total assistance in dressing, bathing, and toileting.

Limited ability to speak, loss of ambulatory ability, loss of ability to sit up, smile, hold head up; total care needed.

Note. This material adapted from Reisberg et al. (1987). 
Depression often accompanies AD early in the disease. After the diagnosis of AD has been made, it is still important to consider depression as a possible co-morbid condition and have it diagnosed. There are multiple benefits to the $\mathrm{AD}$ patient and family by having depression diagnosed. Most relevant is that depression can cause additional dysfunction in the AD patient. Antidepressants have been shown to be effective and reduce the disability and improve overall functioning (Alexopoulos, 1996). In the Cache county aging study, apathy was the most commonly reported disturbance among $\mathrm{AD}$ patients and family members. Depression and/or agitation were found in 1 out of 4 of the participants in this study (Lyketsos et al., 2000).

Hallucinations, either auditory or visual in nature, are a symptom found in Alzheimer's disease. The most common hallucinations are seeing things or hearing voices, although patients have been known to feel, smell or taste things as well (Mace \& Rabins, 1991). Psychiatric disturbance is common in $\mathrm{AD}$, however, the inability to reason and appropriately interpret sounds may increase the patient's likelihood of experiencing hallucinations. Delusions, which are false ideas believed by a person, often stem from these hallucinations (Gruetzner, 1992). Delusions in the Alzheimer patient are many times suspicious or selfblaming in nature. These delusions often result from the patient trying to assess their current situation (Mace \& Rabins, 1991). Due to memory or reasoning impairment, situations are often misinterpreted. For example, the patient may be unaware who the housekeeper is. Due to memory impairment, the patient only knows they see a stranger in their home and they react to the person as an intruder (Gruetzner, 1992). Misinterpreting the situation can lead to many of the behavioral issues common in $\mathrm{AD}$ such as not eating due to the belief the food has been poisoned. 
Motor-related behavioral disturbances such as agitation, wandering, pacing, restlessness and repetitive mannerisms are a result of inappropriate perceptions. Niestein and Siegel (1996), state the purpose of human behavior is to "adapt to the perceived environment ( $\mathrm{p}$. 400)." Dementia patients view their environment through a faulty mechanism, which may cause behavior that is inappropriate. Not all motor related behaviors require treatment or intervention. For example, pacing and repetitive mannerisms such as the rubbing together of hands may distress the caregiver, but do not prove problematic for the patient. Neistien and Siegal (1996) argue that the increased motor behavior may be an attempt by the dementia patient to offset the lack of environmental stimulation. These types of disturbances are more frequently found in Alzheimer patients that have more moderate and severe cognitive impairment (Aronson, Post, \& Guastadisegni, 1993). The most frequently cited behavioral problems exhibited by the more severely cognitive impaired patients include the inability to sit or stand still, pacing, and resistance to care such as bathing, dressing, and grooming (Aronson et al., 1993).

Wandering tends to be the most identifiable motor related disturbance associated with Alzheimer's disease. There are multiple explanations as to why the AD patient wanders. Many have to do with the AD patient's interpretation of the environment. For example, Yang, Hwang, Tsai, and Liu (1999) found that Alzheimer's patients with misidentification problems, especially that of "someone is in my house" and "this is not my house", were more likely to wander. Problems with auditory hallucinations and sleep disturbance were also more likely in patients that wander. The main issue with wandering is the harm that can come to a patient when they get lost or wander into the street. The concern of the patient 
getting lost is significant as an estimated $40 \%$ of $\mathrm{AD}$ patients get lost outside of the home (McShane et al., 1998).

Sleep disturbance is found to be high among dementia patients (Alessi et al., 1995). AD patients tend to sleep more during daytime hours and less in the nighttime hours (Meguro et al., 1995). As cognitive impairment becomes more severe, there tend to be more problems with sleep disturbance (Bliwise, Hughes, McMahon, \& Kutner, 1995).

Alzheimer's disease affects the ability for a person to carry out normal every day activities. Abilities such as dressing, bathing and eating refer to activities of daily living (ADL) and tasks such as shopping and using transportation refer to instrumental activities of daily living (IADL). There is recent evidence that decline in ADL's and IADL's often present before a diagnosis of Alzheimer's disease is given (Wilms, Kanowski, \& Baltes, 2000). An examination of the data from the Berlin Aging Study (Baltes \& Mayer, 1999) found that two-thirds of all dementia patients had trouble with the IADL's of transportation and shopping and one-third had limitations including bathing and walking. Grooming and eating appeared to be unaffected prior to diagnosis. When those with dementia also suffered from depression, the numbers jumped to $70 \%$ of the patients experiencing difficulty with the IADL's of transportation and shopping. Difficulty with ADL's went to 50\% with bathing, climbing stairs, walking and bladder control being most problematic (Wilms et al., 2000). Problems in the areas of ADL's can be experienced in either a decline in areas or excessive behavior in areas.

General loss of social inhibitions may leave an AD patient with little regard for his/her personal appearance. Wearing clothes several days in a row is not uncommon as the patient may forget how long it has been since they changed clothes (Gruetzner, 1992). All of the 
choices involved in picking out clothes may also be overwhelming. Other reasons for difficulty in dressing may be the actual task of getting dressed. Items such as zippers and buttons may become difficult to handle (Mace \& Rabins, 1991). Dressing in multiple layers of clothing and the wearing of a coat or sweater in 90 degree weather can also be seen with AD.

Bathing is another area that can be problematic in Alzheimer's disease patients. Fear of bathing is a part of the middle stages of dementia. The patient is often labeled uncooperative when they are unwilling to bathe. The fear of bathing is actually based upon legitimate concerns such as forgetting how to adjust water temperature, how to use soap and water and the fear of falling in or out of the tub. The patient has also lost the ability to recognize personal hygiene as important. Social judgment and awareness are severely affected in AD. Another reason for objecting to bathing is the obvious sign of dependence. Many times a patient may not remember the last time they took a bath and just assume it was this morning or yesterday because that was their normal routine in the past (Gruetzner, 1992).

Problems of urine and bowel incontinence are common. Because many medical problems can produce incontinence problems alternate explanations for such behavior should be explored. Other causes of problems with toileting may be that the patient moves too slowly or the patient is unable to identify the bathroom (Mace \& Rabins, 1991). Unique toileting issues such as urinating in trashcans and excessive worry about needing to void are also typical.

Eating can be disrupted in different ways throughout the course of the illness. A decrease in appetite is common in AD. A patient may also complain of being hungry all the 
time or may experience Hyperphagia (increased amount and frequency of eating) (Yang et al., 1999), which may be related to not being able to remember the last time he/she ate. The ability to chew and swallow food becomes difficult in the final stages of the illness and this ability is eventually lost (Gruetzner, 1992).

\section{Cognitive Deficits}

Memory deficits are the symptom most typically associated with Alzheimer's disease. In the early stages of the illness, patients may complain of difficulty recalling new information, such as recent events or conversation. Learning new material or new procedures present another area of difficulty. The ability to remember short lists, such as for shopping or a daily schedule also creates problems for the $\mathrm{AD}$ patient. In the more advanced stages of the illness, memory impairment becomes more severe overall. Simple routines can no longer be followed and new impairments, such as the inability to recognize faces become a regular issue (Richards \& Stern, 1992). In general, memory can be classified on multiple levels; temporal aspects (immediate, short-term, long-term, and remote), type of information being processed (verbal, visual, etc.), or the nature of the processing (priming, encoding, recall, recognition). There is a large body of evidence that supports most all aspects of memory is affected by Alzheimer's disease (Richards \& Stern, 1992), as discussed more fully next.

Short-term, or primary, memory refers to the ability to retain information over a very brief period of time, typically one minute or less. The ability to remember new information is highly impaired in AD. Research supports this impairment along with specific impairments in immediate registration and maintenance of information in working memory. Long-term storage of new information is also impaired in AD. Multiple studies suggest a 
deficit in encoding and organization of material for long-term storage [see Richards \& Stern, 1992, for more information].

In contrast to primary and secondary memory, there is evidence that remote memories remain better preserved in $\mathrm{AD}$. Remote memories refer to the preservation of memories from the distant past. A large portion of remote memory remains intact, at least in the early stages of the illness. However, when AD patients are compared with controls, there is a decrease in remote memory (Cherry \& Plauche, 1996). When compared with Parkinson's disease patients, AD patients also show a greater deficit in remote memory (Fama et al., 2000). The current belief is that AD patients have a deficit in their ability to efficiently access remote memories rather than decay of the material involved in remote memory itself (Richards \& Stern, 1992).

Research has addressed the areas of episodic and semantic memory loss in AD patients. Episodic memory refers to autobiographical memories; the memories for events that are personally experienced in unique spatial and temporal contexts. Semantic memory refers to a person's knowledge of words and concepts. There is evidence that episodic memory remains more intact than semantic memory in AD patients (Nebes, 1993) [for further review of memory deficits in AD see Cherry \& Plauche, 1996, Parasuraman \& Nestor, 1993 and Richards \& Stern, 1992].

A key symptom of $\mathrm{AD}$ is progressive intellectual decline. In the early stages there is a deficit in new learning, spatial disorientation develops, and word-finding pauses in conversations appear. Patients often begin to exhibit poor judgment and difficulty in reasoning through problems. The later stages can include amnesia syndromes, aphasia, 
agnosia, apraxia, and delusional thinking. The final stages show intellectual capacities almost completely impaired (Huff, 1988).

Attentional capacity deficits in AD have been explored in a number of studies. The distinction between controlled processes and automatic processes are helpful in pinpointing where the deficits in AD exist. Controlled processes refer to effortful mental operations, such as the intentional use of a strategy to facilitate knowledge acquisition. Controlled processes demand large attentional capacity. In contrast, automatic processes occur without conscious effort (Shriffrin \& Schneider, 1977). In the early stages of the illness, the controlled processes are impaired. Automatic processes, which require less attentional processing, do not seem to be affected until the later stages of the illness (Richards \& Stern, 1992). AD patients tend to have difficulties with tasks that have a controlled processing component, such as tasks in which unfamiliar material is presented, and tasks involving active retrieval from long-term memory. Patients with AD tend to have less difficulty with tasks that include a more automatic processing component such as vocabulary, reading familiar words and naming familiar objects. These performance differences support the existence of an attentional capacity deficit in AD (Richards \& Stern, 1992).

Another area of focus has been in divided verses focused attention. Baddeley's (1996) central executive research found preliminary evidence of a dual-task processing deficit in persons with probable AD. AD patients, in comparison to healthy older adults, had more difficulty performing two tasks simultaneously. A follow up study by Baddeley, Baddeley, Bucks and Wilcock (2001), found similar results as well as support for a fractionated executive control deficit in comparison to a more global central executive deficit. Overall, AD patients show severe impairments in their ability to divide attention while focused 
attention appears to remain intact [for further information on attentional issues in $\mathrm{AD}$, see Baddeley, 1996, Parasuraman \& Nestor, 1993, \& Richards \& Stern, 1992].

Huff (1988) describes the nature of language impairment in AD. Accordingly, the presence of language disorder is consistent by the middle stages of AD (Huff, 1988). Specific deficits in language coincide with the different stages of AD. See Table 4 for the typical pattern of progression of language disorder in AD.

Table 4: Typical Pattern of Progression of Language Disorder in Alzheimer's $\underline{\text { Disease }}$

Early symptoms

Difficulty in finding substantive words

Word-finding pauses

General vocabulary use due to difficulty in naming objects

Late symptoms

Phonemic (e.g., $\log$ for $d o g$ ) \& Semantic (e.g., cat for $d o g$ ) substitution errors Simplified syntax Impaired comprehension

Final symptoms

Meaningless repetition of words

Repetition of nonsense sounds

Mutism

Note. Adapted from Huff, 1988.

Azuma and Bayles (1997) address the direct relationship memory impairment has on the language abilities of the AD patient. Dementia patients exhibit deficits in auditory comprehension and topic maintenance. Reference errors and the use of sentence fragments in their spoken language are common. The use and remembering of sentence content is 
another area of difficulty. Syntactic and phonological knowledge remains intact as evidenced by the grammar and pronunciation of the intact spoken language of the AD patient. Dementia patients keep the ability to read aloud even after the ability to understand such material is lost. AD patients also experience deficits in the meaning of language. These semantic deficits include the inability to use and comprehend meanings of words as well as difficulties in reference and contextual aspects of language (Azuma \& Bayles, 1997) [For further discussion of language deficits in AD see Azuma \& Bayles, 1997 \& Huff, $1988]$.

Three common symptoms associated with the language deficit are anomia, agnosia, and aphasia. Anomia is impairment in naming. Many times a patient will refer to an item by the name of another member of the item's semantic category. For example a patient may call an apple an orange. The patient may describe what the object does but is unable to retrieve the appropriate word (Huff, 1988). Agnosia is the inability to recognize objects. This inability to recognize often extends to places such as a person's home, and to persons such as family members (Gruetzner, 1992). Aphasia is a problem with speaking and understanding language. Abilities in language comprehension and/or production are gradually lost. There is a decrease in the ability to understand speech and verbally express oneself (Gruetzner, 1992). A study by Yesavage, Brooks, Taylor and Tinklenberg (1993) found an association between early onset aphasia and scores on the Mini Mental State Exam (MMSE). Early onset aphasia is associated with an accelerated decline on the MMSE. This finding is consistent with the idea that early onset of language dysfunction in Alzheimer's disease is associated with a more rapid clinical decline. 


\section{Interventions}

Generally speaking, memory improvement techniques that are efficacious for older adults have not proven successful with Alzheimer's patients (Yesavage, 1982). Overall, Alzheimer's patients have shown little benefit from memory interventions, such as those techniques that rely on organizations or association, which are often used with other populations. Yesavage (1982) looked at the effectiveness of memory training and degree of cognitive impairment as measured by the MMSE. Scores on the MMSE can range from 0 to 30 with a score of 0 being the most cognitively impaired to a score of 30 being cognitively intact. Those patients with scores of 18-24 on MMSE showed some improvement with the use of mnemonics but there was no evidence of practical improvement. Participants with MMSE scores of 18 and below did not benefit from the memory training at all. Hill, Yesavage, Sheikh, and Friedman (1989) found mental status is positively related to memory performance changes. This study used 2 types of visual-imagery mnemonics. Persons with higher MMSE scores (29 and 30) show increased improvement on name-face recall. Patients with MMSE scores lower than 29 showed only minimal improvements. Even persons with only mild cognitive impairment are not likely to benefit from these memorytraining techniques.

Camp, Foss, O'Hanlon and Stevens (1996) also point out that techniques that have been successful with the normal population tend to be largely unsuccessful in persons with Alzheimer's disease. Backman (1992), in Camp et al., (1996), spoke specifically of such interventions being unsuccessful, "When training procedures involving, for example, imagery or organization have been used with Dementia Alzheimer's Type patient, gains have generally been small or nonexistent. The lack of gains from memory training in DAT is not 
surprising considering that the methods used are based on strategies that require a considerable amount of cognitive effort and associative skills that are severely impaired in DAT" (p. 85). The evidence supporting the inefficiency of normal memory techniques with Alzheimer's disease patients has led researchers to focus on alternative interventions, mainly the use of spaced-retrieval.

Spaced-retrieval (S-R) is a technique used to aid mnemonic function. Landauer and Bjork (1978) were the first to develop this methodology using a college student population. Spaced-retrieval utilizes shaping procedures and applies them to the acquisition and retention of information in memory (Abrahams \& Camp, 1993). In spaced-retrieval, information is learned and retained by making active recall attempts over increasingly longer periods of time. A person is taught a piece of information (e.g. a name) and repeatedly tested at retention intervals that systematically lengthen over successful recall trials. If the person correctly recalls the information the retention interval is increased. If the person is unsuccessful in their recall attempt, the information is restated to them and the next retrieval interval is reduced to the previous interval (Camp et al., 1996).

There are many benefits of spaced-retrieval as a technique for older adults with probable AD. One benefit is that the technique is utilized in the context of a social visit, which creates a positive experience for the patient. Another advantage is the simplicity of the paradigm itself. The time intervals in spaced-retrieval are basically a form of shaping the desired response. Even in failure the intervals are adjusted to ensure the patient achieves success. The last advantage is that this intervention appears to work without conscious effort in that the patient learns with minimal effort (Camp \& Stevens, 1990). 
Camp et al. (1996) had success in teaching patients with MMSE scores from 11-26 to use a calendar. The majority of participants learned to use the calendar without assistance from a caregiver in 2-3 training sessions (61\%), and an additional $26 \%$ learned the strategy after 4 sessions. The intervention was designed to teach patients to look at the calendar every day and read the task they were to do (e.g. take out the garbage). Participants were also asked to sign the calendar after they had read the calendar. A large percentage of patients $(81 \%)$ learned to sign the calendar after usage. The study follows usage for 1 week but many participants continued with the calendar usage well after the study had finished (see Camp et al., 1996).

McKitrick, Camp, and Black (1992) found that dementia patients were able to successfully complete a prospective memory task after training with the spaced-retrieval technique. The task involved the participants selecting a colored coupon and giving it to the experimenter after a one-week delay. The patients were successful on the task and were also able to make changes within the task such as remembering to give the experimenter a different colored coupon. McKitrick et al.'s study supports that spaced-retrieval is successful in teaching dementia participants prospective memory tasks as well as successfully teaching a change task requirement (McKitrick et al., 1992).

The spaced-retrieval method has also proven successful in aiding older adults with probable Alzheimer's disease with remembering names of persons and common objects. Camp and Schaller (1989) trained a man with Alzheimer's disease in the spaced-retrieval method to remember and utilize a caregiver's name. At a six-month follow up, the patient was consistently calling the nurse by her name (Camp \& Schaller, 1989). In Abrahams and Camp (1993), patients were trained using the spaced-retrieval method to recall common 
objects. Patients were shown a target item and asked to name it. If they could not name the item they were given the correct name and immediately asked to repeat it. Time intervals were increased with each successful recall. If the patient failed to recall the item the name was given and the recall interval was reduced. By the end of the first day, one participant had 5 errors in 25 trials. Two weeks later, the participant was able to recall the target item at the beginning of the training session. The patient was also capable of identifying a colored drawing of the item. Another participant also had success utilizing the spaced-retrieval technique. This participant had 3 errors out of 22 trials at the end of the first day and at 2 weeks was able to name the target item at the beginning of the session (Abrahams \& Camp, 1993).

Cherry, Simmons, and Camp (1999) also found spaced-retrieval to be effective in aiding the recall of everyday objects. Participants were trained utilizing the spaced-retrieval method to identify a target object out of a group of objects. The participants were considered successful if they were able to pick the correct item and hand it to the experimenter on cue. Spaced-retrieval produced within and across training session benefits. Final retention of the participants was increased from 3 to 5 times that of retention in the first trial.

McKitrick and Camp (1993) found spaced-retrieval useful, for not only recalling previously known objects, but also learning the names of new objects. A caregiver trained a woman experiencing anomia in the spaced-retrieval technique. This woman scored a 14 on the MMSE. The woman had 10 weekly visits that lasted approximately an hour. The target objects were the names of familiar objects from the Boston Naming Test (Kaplan, Goodglass, \& Weintrub, 1983). In addition to these objects, the patient was taught to 
remember personal names she had forgotten such as her favorite tree's name, table lamp and her caregiver's name. In addition to forgotten items the participant was able to learn the name of a new item, a computer floppy disc. The results of this intervention were an overall success in that all trained items were learned and produced with greater consistency than before spaced-retrieval training was implemented.

Alexopoulos (1994) utilized the spaced-retrieval technique to discontinue a patient's inappropriate sexual behavior. Spaced-retrieval was used in treating a patient with severe cognitive impairment (score of 8 on the MMSE) who was exhibiting sexually inappropriate behavior that included touching and verbal remarks to female patients and staff members. The participant was given a written statement that said "Ward rule: No touching females on the ward." He was asked to read the note and was asked what the rule was. After spacedretrieval training was implemented the behavior eventually stopped. It became unnecessary to ask the patient to read the rule (Alexopoulos, 1994).

Spaced-retrieval has been used in combination with fading cues to achieve success in discontinuing several problem behaviors found in Alzheimer's disease. Bird, Alexopoulos, and Adamowicz (1995) describe fading cues as graded cues sequentially given to the participant on each learning trial until retrieval occurs. The cue levels are slowly decreased or faded across trials and memory trace is consolidated. The cue is designed to assist in the recall of practical information. Many times interventions with AD participants prove unsuccessful because the patient never learns the association between the cue and object or behavior. For example, a door painted red is supposed to act as a cue for the restroom. This intervention is useless if the participant is never capable of understanding what the red door means. This study taught participants to associate a specific cue with a behavior or with 
information that was intended to modify behavior utilizing the spaced-retrieval method. The first participant was taught to associate a cue, a large colored sign, with the location of the toilet. The participant had been voiding in inappropriate places. The intervention was a success and inappropriate voiding was no longer a problem. The second participant had aggressive and disruptive behavior such as wandering into others rooms and taking others belongings. In a single two-hour session, the participant was taught that a red stop sign means to stop and walk away. Daily entries into others rooms dropped from an average of 43 to 2 per day. The third participant had a fear of soiling himself. He was taught to associate a beeper going off to signal the time to go to the bathroom. The participant slowly progressed to 2-hour intervals of the beeper. At follow up a year later the participant continued to use the beeper and displayed no anxiety in between trips to the restroom.

Bird and Kinsella (1996) had success with participants being able to associate a task with a cue. Participants were taught using spaced-retrieval to identify an alarm with the task of opening a book and reading a card. The study explored if better recall would occur if the participant actually performed the task that was on the card rather than just reading it. Performing the task proved insignificant in better recall but over $50 \%$ of the participants learned to recall the task by the alarm alone. 


\section{SPECIFIC AIMS}

Steady decline in cognitive functioning is an irreversible symptom of Alzheimer's

disease. However, there is growing evidence to suggest that it is possible to implement memory interventions that build on the remaining cognitive abilities of persons with AD. The spaced-retrieval technique has proven to be a successful memory intervention with AD patients (Camp, Bird \& Cherry, 2000). Spaced-retrieval has shown to be useful in learning new information and recalling that information over significant periods of time (Camp et al., 2000). The spaced-retrieval technique, more specifically, has proven successful with the AD population in enhancing recall of the names of objects (Cherry et al., 1999). Camp and Schaller (1989) successfully used spaced-retrieval to train an AD patient to remember his caregiver's name. The results of Cherry et al. (1999) support that spaced-retrieval is a viable technique of memory enhancement of single item information in persons with AD. The current research is designed to extend Cherry et al.'s earlier findings with objects to facename associations. There are two main objectives in the present research. The first goal of the study was to adapt the spaced-retrieval training procedure to help AD clients learn and retain face-name associations. The second goal was to determine whether the face-name training transfers to an actual person. These two goals are discussed in more depth below.

The first aim is to adapt the spaced-retrieval training procedure to help older adults with probable AD learn and retain face-name associations. Using an adapted version of Cherry et al.'s method and procedures we expected to demonstrate the flexibility of the spacedretrieval technique to promote the learning and recall of face-name associations in AD clients. Our results should also demonstrate the positive effects of the spaced-retrieval 
technique and provide further validation of its viability as an intervention with persons with probable AD.

The second goal is to determine whether the face-name training transfers to an actual person. Camp and Schaller (1989) have shown that spaced-retrieval can be a successful technique in training a client to recall a caregiver's name. In the present research, the participants were trained using spaced-retrieval to learn a face-name association. We included transfer trials to determine whether this learning transfers to the actual person pictured in the face photograph. Finding that the training proves to be transferable from picture to an actual person would have practical implications for the use of spaced-retrieval in an applied setting. 


\section{MATERIALS AND METHODS}

\section{Participants}

A total of 6 persons with probable $\mathrm{AD}$ were recruited from a local Baton Rouge adult day care center. All participants had a chart diagnosis of adult dementia and met the DSM IV (American Psychiatric Association, 1994) criteria for dementia of the Alzheimer's type. On the Global deterioration Scale (Reisberg, Ferris, deLeon, Crook, \& Hayes, 1987), all participants were representative of Stage 4 to 5 dementia which is considered mild to moderate AD. A summary of demographic and health characteristics of the sample is located in Table 5 and Table 6 . Table 5 includes information reported by the primary caregivers, while Table 6 is self reported information. ${ }^{1}$

Participants were assigned to one of the following spaced-retrieval training schedules: a consecutive day schedule (i.e. T, W, Th) or an alternate day schedule (M, W, F). Previous research using this paradigm had used the alternate day schedule for all participants. However, due to practical considerations, more specifically participant schedules, the addition of a consecutive day schedule was necessary. The different training schedules were treated as an independent variable in this study to provide new evidence on the possible influence of training schedule on spaced-retrieval performance.

\section{Individual Difference Measures}

To obtain a cognitive profile of each participant, the following measures were completed: the Mini Mental State Exam (MMSE), the Geriatric Depression Scale (GDS), short-form of the WAIS, and a series of participant-performance tasks.

\footnotetext{
${ }^{1} \mathrm{~S} 1$ was a pilot subject. She was unable to complete all training sessions therefore her data is not included here.
} 
Table 5: Summary of Demographic and Health Characteristics (caregiver-reported)

\section{Participants}

\begin{tabular}{|c|c|c|c|c|c|c|}
\hline Measure & $\mathbf{S 2}$ & S3 & S4 & S5 & S6 & S7 \\
\hline Age & 81 & 86 & 88 & 87 & 83 & 80 \\
\hline Gender $^{\mathrm{a}}$ & 2 & 2 & 2 & 2 & 1 & 2 \\
\hline Race $^{b}$ & 2 & 1 & 1 & 1 & 1 & 1 \\
\hline Marital status $^{\mathrm{c}}$ & 4 & 4 & 4 & 4 & 2 & 4 \\
\hline Years of education $^{\mathrm{d}}$ & 4 & 2 & 4 & 2 & 4 & 4 \\
\hline Occupation level $^{\mathrm{e}}$ & 3 & 3 & 3 & 3 & 3 & 3 \\
\hline No. of chronic diseases ${ }^{\mathrm{f}}$ & 1 & 1 & 0 & 2 & 3 & 1 \\
\hline No. of physician visits in past year ${ }^{\mathrm{g}}$ & 3 & 3 & 2 & 4 & 4 & 3 \\
\hline No. of hospital stays in past year ${ }^{\mathrm{h}}$ & 1 & 1 & 1 & 2 & 2 & 1 \\
\hline $\begin{array}{l}\text { No. of physician prescribed } \\
\text { medications }{ }^{i}\end{array}$ & 3 & 2 & 1 & 3 & 3 & 3 \\
\hline
\end{tabular}

Note. ${ }^{\mathrm{a}} 1=$ male, $2=$ female. ${ }^{\mathrm{b}} 1=$ white, $2=$ black. ${ }^{\mathrm{c}} 1=$ single, $2=$ married, $3=$ divorced, $4=$ widowed. ${ }^{\mathrm{d}} 1=$ less than $7^{\text {th }}$ grade, $2=7^{\text {th }}-9^{\text {th }}$ grade, $3=10^{\text {th }}-11^{\text {th }}$ grade, $4=$ high school degree, $5=$ partial college or specialized training, $6=$ college degree, $7=$ graduate degree. ${ }^{\mathrm{e}} 1=$ unskilled, $2=$ semi-skilled, $3=$ skilled, $4=$ semi-professional, $5=$ professional. Professions included, seamstress, homemaker, dietician and farmer. ${ }^{f}$ higher scores reflect more health problems. ${ }^{\mathrm{g}-\mathrm{i}} 1=$ none, $2=1$ to $3,3=4$ to $6,4=$ over 6 . 
Table 6: Summary of Health and Social Activity Characteristics (self-reported)

Participants

\begin{tabular}{lcccccc} 
Measure & S2 & S3 & S4 & S5 & S6 & S7 \\
\hline $\begin{array}{l}\text { Self-perceived health } \\
\text { a }\end{array}$ & 1 & 1 & 1 & 3 & 3 & 2 \\
$\begin{array}{l}\text { Health prevents activities } \\
\text { bealth compared with others }\end{array}$ & 1 & 1 & 1 & 2 & 2 & 2 \\
$\begin{array}{l}\text { No. of times per week for } \\
\text { visitors }\end{array}$ & 4 & 2 & 2 & 3 & 2 & 2 \\
$\begin{array}{l}\text { No. of activities at SFH per } \\
\text { week }\end{array}$ & 3 & 4 & 4 & 2 & 2 & 1 \\
$\begin{array}{l}\text { No. of community activities } \\
\text { outside home }\end{array}$ & 2 & 2 & 2 & 2 & N/A & 2 \\
$\begin{array}{l}\text { No. of hours per week spent } \\
\text { outside of home }\end{array}$ & 4 & 5 & N/A & 2 & 3 & 4 \\
\hline
\end{tabular}

Note. All ratings were made on a 3 to 5 -point Likert scale. ${ }^{\mathrm{a}} 1=$ excellent to $4=$ poor. ${ }^{\mathrm{b}} 1=$ not at all to $3=$ a great deal. ${ }^{\mathrm{c}} 1=$ better to $3=$ poorer. ${ }^{\mathrm{d}}$ higher scores reflect increased number of times. ${ }^{\mathrm{e}, \mathrm{f}}$ higher scores reflect more activities. ${ }^{\mathrm{g}}$ higher scores reflect more time. $\mathrm{N} / \mathrm{A}=$ no answer given.

Table 7 contains a summary of all measures of individual differences administered to each participant. The MMSE (Folstein, Folstein, \& McHugh, 1975) was used to provide an index of current cognitive status. The maximum score on the MMSE is 30. On this measure, healthy older adults scores range from 27 to 30 . For the current sample, scores range from 5 to 20, indicating cognitive impairment (see Table 8). 
Table 7: $\quad$ List of Individual Difference Measures Given To Participants

$\underline{\text { Measure/Reference }}$

Mini-Mental State Exam (MMSE)

Folstein, Folstein \& McHugh, 1975

Geriatric Depression Scare (GDS)

Yesavage et al., 1983

Vocabulary test, short form

Jastak \& Jastak, 1965

Forward Digit Span (FDS)

Backward Digit Span (BDS)

(WAIS, 1955)

Subject-performed tasks (SPT)

Cherry, Moore \& Kelley, 1996

\section{$\underline{\text { Purpose }}$}

Cognitive screening measure

Affect screening measure

General intellectual

functioning

Short-term memory

Working memory

Secondary memory

measure

To obtain a measure of affective status, the GDS (Yesavage et al., 1983) was

administered. Scores between 6 and 10 on the GDS represent mild depression. The scores from the current sample ranged from 0 to 4 , indicating all participants were within the normal range and did not appear to be suffering from depression at the time of testing (see Table 8). The short-form of the WAIS vocabulary test (Jastak \& Jastak, 1965) was utilized as a measure of general intellectual functioning as well as verbal ability. A maximum score of 40 is possible on the vocabulary subtest. Past research utilizing the short form of the WAIS yielded a mean verbal score of 16.1 for lower education adults and a mean verbal score of 29.7 for higher education older adults (Cherry \& Park, 1993). Participant scores form this sample ranged from 6 to 13, indicating a deficiency in general intellectual functioning and verbal ability. 
The Forward Digit Span and the Backward Digit Span from the WAIS were used to obtain a measure of short-term memory and working memory, respectively. The highest possible score is 9.0 on the FDS and 8.0 on the BDS. On the FDS, the current sample scores were between 3.5 and 5.0, suggesting deficits in short-term memory. Scores on the BDS were between 0 and 3.0, suggesting working memory impairment (see Table 8). The pattern observed in the present population of higher scores on the FDS in comparison with the BDS is also found in populations of health older adults.

Lastly, participants were given series of participant-performed tasks adapted form Cherry, Moore, and Kelley (1996) as a measure of secondary memory ability. In this task 10 items were presented and participants were asked to perform a specific action with each item. For example, the experimenter handed the participant a rubber band and said, "Here's a rubber band, I want you to stretch the rubber band." Participants were later asked to free recall the object and what they did with the object. For items that were not recalled, the object was presented as a cue and participants were asked to describe what they did with the object.

The task was scored based on a strict (i.e., verbatim) and lenient (i.e., semantically parallel) criteria for both free recall and cued recall of the objects and the actions. Overall, free recall of the objects and actions were low, regardless of implementing the strict or lenient criteria, as can be seen in Table 8. This finding is consistent with the literature on $\mathrm{AD}$, in that memory impaired persons with probable $\mathrm{AD}$ show gross deficits on measures of secondary memory (Cherry \& Plauche, 1996). Memory for the object and action improved when the participants were presented with the object as a cue in the cued sample. The 
Table 8: $\quad \underline{\text { Summary of Individual Difference Measures }}$

Participants

\begin{tabular}{|c|c|c|c|c|c|c|}
\hline Measure & $\mathrm{S} 2$ & $\mathrm{~S} 3$ & S4 & S5 & S6 & S7 \\
\hline Age & 81 & 86 & 88 & 87 & 83 & 80 \\
\hline $\mathrm{MMSE}^{\mathrm{a}}$ & 14 & 14 & 19 & 17 & 5 & 20 \\
\hline $\mathrm{GDS}^{\mathrm{b}}$ & 4 & 0 & 0 & 3 & 1 & 2 \\
\hline Vocabulary $^{c}$ & 12 & 11 & 8 & 7 & 6 & 13 \\
\hline $\mathrm{FDS}^{\mathrm{d}}$ & 5.0 & 4.0 & 4.0 & 4.0 & 3.5 & 5.0 \\
\hline $\mathrm{BDS}^{\mathrm{d}}$ & 1.0 & 3.0 & 3.0 & 3.0 & 0 & 4.0 \\
\hline \multicolumn{7}{|c|}{ Subject Performed Tasks } \\
\hline \multicolumn{7}{|l|}{ Free Recall } \\
\hline Correct (S) & 0 & 1 & 0 & 3 & 0 & 0 \\
\hline Correct (L) & 0 & 1 & 0 & 0 & 0 & 1 \\
\hline Guesses & 0 & 0 & 0 & 0 & 0 & 0 \\
\hline \multicolumn{7}{|l|}{ Cued Recall } \\
\hline Correct (S) & 4 & 6 & 5 & 7 & 4 & 8 \\
\hline Correct (L) & 1 & 1 & 2 & 0 & 2 & 1 \\
\hline Guesses & 0 & 0 & 0 & 0 & 0 & 0 \\
\hline
\end{tabular}

${ }^{\mathrm{a}}$ Mini-Mental State Exam (MMSE, Folstein, Folstein, \& McHugh, 1975).

${ }^{\mathrm{b}}$ Geriatric Depression Scale (GDS, Sheikh \& Yesavage, 1986).

${ }^{c}$ Vocabulary Score, Short-Form of the WAIS Vocabulary test (Jastak \& Jastak, 1965).

${ }^{\mathrm{d}}$ Forward Digit Span (FDS) and Backward Digit Span (BDS) from the Wechsler Adult

Intelligence Scale (Wechsler, 1955).

${ }^{\text {e}}$ Subject-performed tasks (SPT) (Cherry, Moore,\& Kelley, 1996). 
improvement of participants in the cued recall task stresses the importance of computing separate scores for free recall and cued recall.

\section{Baseline Measures of Memory}

Two secondary memory tasks were given at each training session; the prospective nametag task and the shirt color task. The prospective nametag task was administered to provide a baseline measure of memory to perform a simple association, a motor response to a verbal cue, without the benefit of spaced-retrieval training. The purpose of the shirt color naming task was to obtain a baseline measure of delayed recall (either 24- or 48- hours) of a single piece of information, the shirt color from the previous session, without the benefit of spaced-retrieval training. These tasks are described in more detail next.

Prospective Nametag Task. The nametag task was introduced at the beginning of the first session and was included at the beginning of every session thereafter. Both the experimenter and the participants were given a nametag to be worn during each session. The participants were asked to give their nametag back to the experimenter at the end of each session. The participants would know it was the end of the session when the experimenter said, "We are finished for the day." The participants were asked to repeat the instructions back to the experimenter to ensure understanding of the task. If the participants did not spontaneously hand in the nametag when they heard the cue phrase, the experimenter prompted the participants to do so.

The nametag task was scored as follows. If the participant remembered to turn in their nametag when the experimenter heard the cue phrase, "We are finished for the day," 4 points were awarded. If the participant turned in their nametag after the cue phrase, "We are finished for the day" had been repeated twice, 3 points were given. If the participant turned 
in their nametag only after the experimenter touched their own nametag (a cue) and repeated the cue phrase three times, 2 points were awarded. If the participant turned in their nametag only after the experimenter first touched their own nametag (a cue), repeated the cue phrase four times and took off their own nametag, 1 point was given. If the participant did not remember to turn in their nametag after all of the above cues were given, 0 points were awarded. The experimenter then asked for the participant's nametag and asked if they remembered what they were suppose to do when they heard the cue phrase, "We are finished for the day." Each day the participant's responses were recorded and a score awarded. A total score was calculated by summing scores across all nine days.

Shirt Color Naming Task. At the end of each training session the participant was told to remember the color of the shirt that the experimenter was wearing that day. The experimenter always wore a plain colored shirt (e.g., black, white, red, and blue) and told the participant the color of the shirt. The participant was informed to report the color of this shirt to the experimenter at the beginning of the next session. Participants were asked to repeat the instructions to ensure they understand the procedure. At the beginning of the next session if the participant did not spontaneously report the color of the shirt, the experimenter prompted the participants to see if they remembered the task. If the participants were still unable to recall the color, they were prompted to specifically name the color of the shirt. This baseline measure of memory was scored as pass or fail. All prompts and responses were recorded.

\section{Summary of Spaced-Retrieval Training Program}

Materials. Ten color photographs of faces, taken from a church pictorial directory, were used as stimuli in the experiment. The pictures were of adults in an age range from 
twenties through fifties. Race was held constant to avoid the memory strategy of recalling the target picture based on race alone. Gender was varied to ensure the task difficulty level was not extreme. One of the photographs was designated as the target item and the other 8 were distracter items. The pictures were laminated and mounted on a 6-x 6-cm piece of foam board to ensure ease in picking up the photos. The photos were presented on a flat wooden board (29-x 29-cm) with scored lines to represent a 3 x 3 matrix.

Training Sessions. The spaced-retrieval training sessions were conducted as follows. First, the experimenter chatted informally with the participant at the beginning of each training session to establish rapport. Next, a $3 \times 3$ matrix was placed on the table in front of the participant. The experimenter presented the pictures individually, naming each one (e.g. "this is Bob") until all 9 pictures were placed on the board with one photo in each position on the matrix. The participants were then introduced to the sound of the beeper. This was done to ensure all participants were able to hear the sound that they would be trained to respond to during the upcoming trials.

The participants were told to select the "correct" picture and give it to the experimenter on cue. For example, "When the buzzer sounds, I want you to hand me the picture of Johnny and tell me his name is Johnny." A correct target response consisted of a visual cue (selecting the correct picture), a motor response (handing it to the experimenter), and a verbal response (saying the target's name). This trained the association of the visual cue with the motor and verbal response. All three responses had to be demonstrated within a trial in order for the trial to be considered successful. After each recall trial, the position of the correct target item was changed to ensure that participants were learning the name-face 
association, and not merely the spatial location of the picture. The time limit for the trials was set at 30-minutes or until the participant expressed fatigue.

The spaced-retrieval technique was used to train this target response. A hand held stopwatch was used to control the trials utilizing the following retention interval schedule: the first retention interval was five seconds. If successful, the following intervals were 10, 20, 40, and 60 seconds. After a successful 60-second retention interval was demonstrated, retention intervals were increased by 30 seconds, contingent on a successful recall. After a 180 -second ( 3 minute) retention was demonstrated, the intervals were expanded by 60 seconds following each successful recall. After a 360 second (6 minute) retention was demonstrated, the intervals were expanded by 120 seconds (for more details, see Cherry \& Simmons-D’Gerolamo, 1999).

\section{Explicit Memory for the Trained Object}

Three different measures of explicit memory were administered to measure the participants' retention of the name-face association trained by the spaced-retrieval method. These include: a) immediate recall and recognition of the trained name-face association (within session explicit control task), b) 24- or 48- hour delayed recall of the trained name-

face association (from one training session to the next), and c) final recall and recognition of the name-face association across the three training sessions (recall of the association acrosssessions). A more detailed description of these tasks follows.

Immediate Recall/Recognition. At the end of each spaced-retrieval training session participants were asked to recall the person's name that they had just been trained on. If the participant was unable to recall the person's name then all nine pictures were placed on the 
table in front of the participant. The participant was then asked to identify which picture they had been working with that day. All responses were recorded.

Delayed Recall. At the beginning of the session, following a spaced-retrieval training session, participants were asked to recall the picture they had worked with in the previous session. The delayed recall task was designed to determine whether the participants were able to remember the target picture from the session before. If participants were able to recall the target picture, this would be evidence that spaced-retrieval training maintains over time. A score of 0 was assigned if participants were unable to recall the target, whereas a score of 1 indicates the participant successfully recalled the target. The target picture was not presented for recognition after delayed recall, as doing so may have confounded the final recognition measure by having repeated exposures to the trained target after the initial spaced-retrieval training session.

Final Recall/Recognition. The final delayed recall was administered on the session following each completed week of spaced-retrieval training (session 6 and 9). This task determined whether or not participants were able to recall or recognize the target person used during the previous week of training. If participants were unable to recall the target person then all nine pictures were placed in front of the participant. Participants were then told to identify the person they had been trained on the previous week. All responses were recorded.

\section{Live Person Transfer Task}

In sessions 6 and 9, the live person transfer task was administered to determine whether the name-face association trained during the spaced-retrieval sessions transferred to an actual person. The "live" person was the individual whose picture served as the target 
picture during spaced-retrieval training. This "live" person target entered the room, handed the experimenter a phone message and sat in an empty chair at the testing table. The experimenter gave the participant an opportunity to spontaneously recognize the live person target. This task was considered Recall Task \#1.

If the participant gave no response, the experimenter implemented Recall Task \#2 which consisted of the following prompt. The experimenter said, "This is my friend, do you know his/her name?" If the participant said no or did not respond, the experimenter moved to Recognition Task \#1, which includes a further prompt. The experimenter said, "Her picture is on the board. Would you hand me her picture?" If the participant still did not appear to recognize the target picture as the live target person, one final recognition task was given (Recognition Task \#2). The experimenter handed the participant the correct picture, if they had not already selected it, and said "Take another look at the picture, now can you tell me her name?" All responses were recorded.

\section{Final Face Recognition Task}

On the last day of the experiment, participants were given a chance to identify all pictures that had been used as stimuli in the spaced-retrieval training sessions. This task was included as a manipulation check to determine whether participants would remember facial pictures given only exposure to the stimuli during the spaced-retrieval training. All nine photographs from the training sessions, as well as nine new photographs the participants had not seen before, were placed on the table. Participants were informed that some of the pictures they had seen before, while others were new pictures that they had not seen before. The participants were asked to hand the experimenter the photographs that they had seen before in previous sessions. All responses were recorded. 


\section{Procedure}

Individual sessions were conducted in a private area at the adult day care center. A total of nine individual training sessions were conducted with each participant. All sessions were held either on three alternate days of the week, or on three consecutive days of the week, across a four-week period. The sessions lasted for approximately one hour. For all participants, informed consent was obtained from the patient's legal guardian in advance of their participation in the study. The sessions were conducted as described next (see Table 9 for a summary of each session).

Day 1: Informed consent was obtained from the participant on the first day. Three individual differences measures were administered; the FDS, MMSE, and the GDS. In addition, the two baseline measures of secondary memory, the nametag task and shirt-color task were given.

Day 2: On the second day, the shirt-color task was administered first. The prospective memory instructions were then stated and the nametags were handed out. Three additional individual difference measures were administered; the BDS, SPT, and a Vocabulary test. The posttest nametag task was given.

Day 3-5: The prospective shirt color task and nametag task were given at the beginning of the session. The instructions for the spaced-retrieval paradigm were given and the training trials began. The posttest nametag task was administered. Responses were recorded on prepared sheets.

Day 6: The prospective shirt-color task and the nametag task were administered. The final delayed recall task was administered for the target picture. The live person transfer task followed. The "live" person target entered the room and the participant was asked to 
recall/recognize the target person. Spaced-retrieval trials began again for the same target picture. Responses were recorded on a prepared sheet. The posttest nametag task was administered. All responses were recorded on a prepared sheet.

Days 7-8: The two-baseline measures of memory, the prospective shirt-color task and the nametag task, were given at the beginning of the session. Spaced-retrieval trials began again and the responses were recorded on a prepared sheet. The posttest nametag test was administered and all responses were recorded.

Day 9: As in all previous sessions, the prospective shirt-color task and the nametag task were administered at the beginning of the session. The final delayed recall task was administered. Next, the live person transfer task was presented, as described earlier. Participants then responded to a demographic questionnaire. The final face recognition task was administered. At the end of the session a "Certificate of Appreciation" was handed out to every participant to express gratitude for the participant's hard work. 
Table 9: $\quad$ Summary of Experimental Procedure

\section{Day 1:}

Informed Consent obtained

Prospective Nametag Task

Forward Digit Span (FDS)

Mini-Mental State Exam (MMSE)

Geriatric Depression Scale (GDS)

Prospective Posttest Nametag Task

\section{Day 2:}

Shirt Color Naming Task

Prospective Nametag Task

Backward Digit Span (BDS)

Participant Performed Task (SPT)

Vocabulary Test

Prospective Posttest Nametag Task

\section{Days 3-5:}

Shirt color Naming Task

Prospective Nametag Task

Delayed Recall (Days 4 - 5)

Spaced-Retrieval Training

Matrix Presented

Instructions Given

Expansion Trials

Immediate Recall/Recognition

Prospective Posttest Nametag Task

\section{Day 6:}

Shirt Color Naming Task

Prospective Nametag Task

Final Delayed Recall/Recognition

Live Person Transfer Task

Spaced-Retrieval Training

Matrix Presented

Instructions Given

Expansion Trials

Immediate Recall/Recognition

Prospective Posttest Nametag Task 
Days 7-8:

Shirt Color Naming Task

Prospective Nametag Task

Delayed Recall

Spaced-Retrieval Training

Matrix Presented

Instructions Given

Expansion Trials

Immediate Recall/Recognition

Prospective Posttest Nametag Task

\section{Day 9:}

Shirt Color Naming Task

Prospective Nametag Task

Final Delayed Recall/Recognition

Live Person Transfer Task

Demographic Questionnaire

Final Face Recognition Task

Prospective Posttest Nametag Task

Certificate of Appreciation handed out 


\section{RESULTS}

\section{Baseline Measures of Memory}

Prospective Nametag Task. The results for the prospective nametag task appear in Table 10. For each participant, a total score was calculated by summing the nametag task score from each of the nine sessions. The highest possible score was 36 points. The results for each participant are as follows: $\mathrm{S} 2=6$ points, $\mathrm{S} 3=17$ points, $\mathrm{S} 4=11$ points, $\mathrm{S} 5=8$ points, $\mathrm{S} 6=0$ points, $\mathrm{S} 7=12$ points. Participants did not initially remember to turn in their nametags when cued to so. Most did not remember to turn in their nametags until session 5, with the exception of S4 who turned in her nametag in session 2. In general, most participants did not remember to turn in their nametags until several cues had been given. $\mathrm{S} 3$ is the exception as she remembered to turn in her nametag in the last four sessions on the first cue. Overall, there is slight improvement in scores for most participants across sessions. ${ }^{1}$

The results of the prospective nametag task provide evidence that repetition alone, even after nine sessions, is not enough to produce a sizeable memorial benefit for memory impaired older adults. It appears that spaced-retrieval training must be utilized in order to observe memorial benefits.

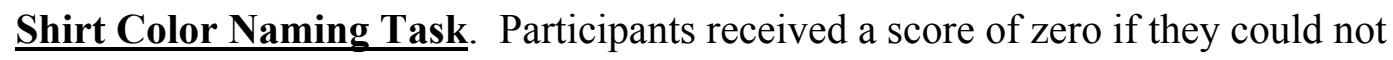
remember the color of shirt the experimenter was wearing in the previous session and a score of 1 was awarded if the participant correctly remembered the shirt color. The participants scores were totaled across sessions and out of a maximum score of 8 the

\footnotetext{
${ }^{1}$ Four of the higher scores on this task (S2 Day 8, S4 Day 5, S5 Day 7, and S7 Day 8) may reflect an abnormality in the session such as the participant's nametag falling off just prior to the implementation of the task.
} 
Table 10: Summary of Nametag Task

Participants

\begin{tabular}{cccccc} 
S2 & S3 & S4 & S5 & S6 & S7 \\
\hline 0 & 0 & 0 & 0 & 0 & 0 \\
0 & 0 & 0 & 0 & 0 & 0 \\
0 & 0 & 2 & 0 & 0 & 0
\end{tabular}

$\begin{array}{lllllll}\text { Day } 4 & 0 & 0 & 1 & 0 & 0 & 0 \\ \text { Day } 5 & 1 & 1 & 4 & 1 & 0 & 1 \\ \text { Day } 6 & 0 & 4 & 0 & 1 & 0 & 2 \\ \text { Day } 7 & 1 & 4 & 2 & 3 & 0 & 4 \\ \text { Day } 8 & 3 & 4 & 2 & 2 & 0 & 3 \\ \text { Day } 9 & 1 & 4 & 0 & 1 & 0 & 12 \\ \text { Total } & 6 & 17 & 11 & 8 & 0 & \end{array}$

Note. Score is based on a maximum score possible of 36.

scores are as follows: $\mathrm{S} 2=0, \mathrm{~S} 3=0, \mathrm{~S} 4=0, \mathrm{~S} 5=1, \mathrm{~S} 6=0, \mathrm{~S} 7=0$. Only 1 participant, $\mathrm{S} 5$, correctly recalled the color of shirt from the previous session and this only occurred once in session 3. After nine days of training all of the participants were still unable to recall the correct color of shirt from the previous session. This finding is consistent with secondary memory deficits observed in the SPT (see Table 8). The results of the shirt color task provide additional evidence that repetition alone is not sufficient to provide memorial benefits with memory impaired older adults. These results, together with those of the nametag task, support the idea that spaced-retrieval training is necessary to receive a memorial benefit. 


\section{Spaced-Retrieval Training Trials}

General Impressions of Performance. Table 11 contains each participant's recall successes, partial successes, failures and longest time interval duration across trials and training sessions. Overall, the positive effect of spaced-retrieval training on recall of the correct name-face association is evident for all participants. To be precise, the number of failed trials (FT) reduced from session 1 to session 6 for all participants. In addition, the longest duration increased for every participant from session 1 to session 6 . That is, all participants were able to retain the correct name-face association for longer retention intervals across training sessions.

Table 12 contains each participant's proportion scores for the partially correct items. The proportion scores were calculated by dividing the number of partially correct trials by the total number of failed trials. Recall, that a correct response consisted of handing the correct photograph to the experimenter as well as stating the correct name. An example of a partially correct response would be selecting the correct photograph but not stating a name.

In general, during the first week of training (i.e. sessions 1-3), most participants showed an increase in the number of partially correct trials, illustrating improvement in the task over sessions. The second week of training (i.e. sessions 4-6) showed more variability. Three participants (S2, S6, S7) continued to show an increase in their proportion scores over the second week. However, S4 and S5 fluctuated from high proportions of partially correct failed trials in session 4, to a drop in session 5 and then back higher in session 6. S3's proportion of partially correct trials falls in session 6 . Note that the number of failed trials 
Table 11: Summary of Spaced-Retrieval Task Performance

\begin{tabular}{|c|c|c|c|c|c|c|c|c|}
\hline & \multicolumn{8}{|c|}{ Participants } \\
\hline & & $\mathrm{S} 2$ & $\mathrm{~S} 3$ & $\mathrm{~S} 4$ & S5 & S6 & S7 & Mean \\
\hline \multicolumn{9}{|l|}{ Session 1} \\
\hline & $\mathrm{FT}$ & 21 & 13 & 38 & 17 & 32 & 15 & 23 \\
\hline & $\mathrm{PC}$ & 1 & 1 & 21 & 11 & 28 & 7 & 12 \\
\hline & $\mathrm{TT}$ & 41 & 28 & 45 & 33 & 43 & 35 & 38 \\
\hline & LD & 40 & 150 & 10 & 90 & 10 & 60 & 60 \\
\hline \multicolumn{9}{|l|}{ Session 2} \\
\hline & FT & 19 & 8 & 31 & 6 & 28 & 18 & 18 \\
\hline & $\mathrm{PC}$ & 1 & 0 & 18 & 6 & 18 & 9 & 9 \\
\hline & $\mathrm{TT}$ & 41 & 22 & 49 & 19 & 32 & 37 & 33 \\
\hline & LD & 60 & 180 & 20 & 150 & 5 & 60 & 79 \\
\hline \multicolumn{9}{|l|}{ Session 3} \\
\hline & FT & 9 & 5 & 24 & 2 & 28 & 19 & 15 \\
\hline & $\mathrm{PC}$ & 3 & 2 & 20 & 2 & 17 & 18 & 10 \\
\hline & $\mathrm{TT}$ & 24 & 18 & 43 & 13 & 41 & 41 & 28 \\
\hline & LD & 120 & 180 & 60 & 240 & 10 & 60 & 112 \\
\hline \multicolumn{9}{|l|}{ Session 4} \\
\hline & FT & 10 & 2 & 19 & 3 & 17 & 13 & 11 \\
\hline & $\mathrm{PC}$ & 4 & 2 & 15 & 3 & 14 & 9 & 8 \\
\hline & $\mathrm{TT}$ & 21 & 14 & 34 & 14 & 33 & 30 & 24 \\
\hline & LD & 90 & 300 & 90 & 240 & 40 & 90 & 142 \\
\hline \multicolumn{9}{|l|}{ Session 5} \\
\hline & FT & 11 & 0 & 9 & 3 & 11 & 11 & 8 \\
\hline & $\mathrm{PC}$ & 5 & 0 & 4 & 2 & 10 & 8 & 5 \\
\hline & $\mathrm{TT}$ & 29 & 12 & 25 & 14 & 24 & 26 & 22 \\
\hline & LD & 180 & 360 & 120 & 180 & 60 & 90 & 165 \\
\hline \multicolumn{9}{|l|}{ Session 6} \\
\hline & FT & 8 & 2 & 4 & 0 & 16 & 1 & 5 \\
\hline & $\mathrm{PC}$ & 5 & 1 & 2 & 0 & 15 & 1 & 4 \\
\hline & $\mathrm{TT}$ & 28 & 15 & 17 & 13 & 29 & 14 & 19 \\
\hline & LD & 360 & 300 & 180 & 480 & 60 & 360 & 290 \\
\hline
\end{tabular}

Note. $\mathrm{FT}=$ Failed Trials, $\mathrm{PC}=$ Partially Correct Failed Trials, TT=Total Trials, LD=Longest Duration 
for these three participants in sessions 5 and 6 is low, which may account for the lower proportion scores (see Table 11).

Table 13a and 13b contain each participant's performance on the live person transfer task. In general, most participants improve in recall and recognition of the target person on week 2 compared to week 1. Most participants recognized the target picture during week 1 even though they did not know her name. By week 2, half of the participants could recall the target by name when asked by the experimenter (i.e., S2, S4, S7). A more detailed analysis of each participant's performance follows.

Table 12: Proportion of Partially Correct Failed Trials

\section{Participants}

\begin{tabular}{|c|c|c|c|c|c|c|c|c|}
\hline & & $\mathrm{S} 2$ & $\mathrm{~S} 3$ & $\mathrm{~S} 4$ & S5 & S6 & S7 & Mean \\
\hline \multirow[t]{3}{*}{ WK 1} & Session 1 & 0.05 & 0.08 & 0.55 & 0.65 & 0.88 & 0.47 & .45 \\
\hline & Session 2 & 0.05 & 0.00 & 0.58 & 1.00 & 0.64 & 0.50 & .46 \\
\hline & Session 3 & 0.33 & 0.40 & 0.83 & 1.00 & 0.61 & 0.95 & .67 \\
\hline \multirow[t]{3}{*}{ WK 2} & Session 4 & 0.40 & 1.00 & 0.80 & 1.00 & 0.82 & 0.70 & .79 \\
\hline & Session 5 & 0.45 & $\begin{array}{c}\text { No failed } \\
\text { trials }\end{array}$ & 0.44 & 0.67 & 0.91 & 0.73 & .64 \\
\hline & Session 6 & 0.63 & 0.50 & 0.50 & $\begin{array}{l}\text { No failed } \\
\text { trials }\end{array}$ & 0.94 & 1.00 & .71 \\
\hline
\end{tabular}

Note. Proportion obtained by dividing partially correct trials by failed trials 
Table 13a: Transfer Task Performance for Alternate Day S-R Schedule

Participants

\begin{tabular}{|c|c|c|c|c|c|c|}
\hline Task & \multicolumn{2}{|c|}{ S4 } & \multicolumn{2}{|c|}{ S5 } & \multicolumn{2}{|c|}{ S6 } \\
\hline & Week 1 & Week 2 & Week 1 & Week 2 & Week 1 & Week 2 \\
\hline $\begin{array}{l}\text { Recall } \\
\text { Question } 1\end{array}$ & 0 & 0 & 0 & 0 & 0 & 0 \\
\hline $\begin{array}{l}\text { Recall } \\
\text { Question } 2\end{array}$ & 0 & 1 & 0 & 0 & 0 & 0 \\
\hline $\begin{array}{l}\text { Recognition } \\
\text { Question } 1\end{array}$ & 0 & --- & 0 & 1 & 1 & 1 \\
\hline $\begin{array}{l}\text { Recognition } \\
\text { Question } 2\end{array}$ & 1 & --- & 1 & 1 & 0 & 0 \\
\hline
\end{tabular}

Table 13b: Transfer Task Performance for Consecutive Day S-R Schedule

Participants

\begin{tabular}{|c|c|c|c|c|c|c|}
\hline Task & \multicolumn{2}{|c|}{$\mathrm{S} 2$} & \multicolumn{2}{|c|}{$\mathrm{S} 3$} & \multicolumn{2}{|c|}{ S7 } \\
\hline & Week 1 & Week 2 & Week 1 & Week 2 & Week 1 & Week 2 \\
\hline $\begin{array}{l}\text { Recall } \\
\text { Question } 1\end{array}$ & 0 & 0 & 0 & 0 & 0 & 0 \\
\hline $\begin{array}{l}\text { Recall } \\
\text { Question } 2\end{array}$ & 0 & 1 & 0 & 0 & 0 & 1 \\
\hline $\begin{array}{l}\text { Recognition } \\
\text { Question } 1\end{array}$ & 1 & --- & 1 & 0 & 1 & --- \\
\hline $\begin{array}{l}\text { Recognition } \\
\text { Question } 2\end{array}$ & 0 & --- & 0 & 0 & 0 & --- \\
\hline
\end{tabular}

Note. $0=$ failed task and $1=$ passed task. 
S2: Detailed Analysis. S2 received spaced-retrieval training for two weeks on an every day schedule (T, W, Th). S2's every day schedule was altered due to a family emergency in week 2. Session 6 was held on a Friday rather than a Thursday, therefore the last day of S-R trials reflects a 48-hour delay rather than a 24-hour delay. In session 1, S2 longest time interval was $40 \mathrm{~s}$. By session 6, S2 had reached a $360 \mathrm{~s}$ retention interval, which is nine times as long as that in session 1. S2's longest duration increased steadily over each session with the exception of session 3 to session 4, which contains a four day delay, when the longest duration drops from $120 \mathrm{~s}$ to $90 \mathrm{~s}$ over these sessions.

In week 1 of the live person transfer task, S2 was unable to recall the target person but was able to recognize the target picture although not remember the target's name. By the second transfer task S2 was able to recall the live target's name when asked by the experimenter. This finding is particularly exciting because it provides evidence that nameface associations trained with the spaced-retrieval method can transfer to a live person.

S3: Detailed Analysis. S3 received spaced-retrieval training for two weeks on an every day schedule (W, Th, F). In session 1, S3 reached a time interval of $150 \mathrm{~s}$. In session 6 that interval increase had doubled to $300 \mathrm{~s}$. S3 showed improvement in her longest time duration over all sessions until session 6 where she drops from $360 \mathrm{~s}$ in session 5 to $300 \mathrm{~s}$ is session 6.

In week 1 of the live person transfer task, S3 was unable to recall the target person. S3 recognized the target picture although she did not remember the target's name. In the second transfer task, S3 was unable to recall or recognize the target person or picture. S3 is the only participant to show deterioration on this task. S3's deterioration may be due to nothing more than a rough day. Her performance is interesting in that, there is no evidence 
that she was unable to retain the name-face association from the previous session, as she was able to recall the target in the final free recall just moments earlier (see Table 16b).

S4: Detailed Analysis. S4 received spaced-retrieval training for two weeks on an every other day schedule (M, W, F). In session 1, S4 reached a longest time interval of only $10 \mathrm{~s}$. In session 6 , the longest time interval increased to $180 \mathrm{~s}$. This shows a retention advantage 18 times that of the first session. S4 showed consistent improvement in her longest duration across sessions.

In week 1 of the live person transfer task, S4 was unable to recall or initially recognize the target, but after being handed the target picture she was able to successfully state the target name. By the second transfer task, S4 was able to recall the live target's name when asked by the experimenter. This finding is particularly striking in that $\mathrm{S} 4$ could retain the name-face association for no more than 10 seconds in session 1 and by the end of training was able to transfer that association to an actual person.

S5: Detailed Analysis: S5 received spaced-retrieval training for two weeks on an every other day schedule (M, W, F). In session 1, S5 reached a 90 s retention interval. By session 6, S5 had reached a retention interval of $480 \mathrm{~s}$, an increase of over five times that of session 1. S5 steadily increased across sessions, with the exception of session 5, in which her longest duration dropped from $240 \mathrm{~s}$ in session 4 to $180 \mathrm{~s}$ in session 5 .

In the first week of the live person transfer, S5 was unable to recall the target and was unable to decisively identify the correct target picture (she picked 2 different target pictures one of which was correct). However, S5 correctly stated the target name after she was told which picture was correct. In week two of the transfer task, S5 was still unable to recall the target. S5 correctly recognized the target picture when cued that the target picture was on 
the board in front of her. She also correctly stated the name of the target. This finding provides evidence of improvement in the task over the two weeks.

S6: Detailed Analysis. S6 received spaced-retrieval training for two weeks on an every other day schedule (M, W, F). In session 1, S6 reached a $10 \mathrm{~s}$ time interval. In session 6, S6 reached a retention interval of $60 \mathrm{~s}$, which is six times that of session 1. S6 drops to a longest time interval of only $5 \mathrm{~s}$ in session 2 but thereafter showed a consistent increase across sessions. This finding is particularly interesting in that S6 is significantly more cognitively impaired, in comparison to the other participants in this sample (see Table 8), and yet shows the ability to retain and recall the name-face association across sessions.

In the first week of the live person transfer task, S6 was unable to recall the target person but was able to recognize the target picture although not correctly name the target. In the second week of the transfer task, S6 performed the same. S6 was the only participant to show no improvement or decline on this task in week 2. This result may be due to lower cognitive functioning. S6 took longer to catch on to the spaced-retrieval task (see Table 11) in comparison to other participants, likewise, he may also need additional training to achieve success on this task.

S7: Detailed Analysis. S7 received spaced-retrieval training for two weeks on an every day schedule (W, Th, F). In session $1, \mathrm{~S} 7$ reached a longest time interval of $60 \mathrm{~s}$. In session 6, the retention level had increased to $360 \mathrm{~s}$. S7 showed a steady increase in longest duration across sessions.

In the first week of the live person transfer task, S7 was unable to recall the target person but was able to recognize the target picture although not state the target name. In week two of the transfer task, the participant was able to recall the live target's name when 
asked by the experimenter. The drastic change from week 1 to week 2 on this task provides additional evidence that spaced-retrieval training can be successful for use in transferring a name-face association to an actual person.

\section{Explicit Memory for the Target Person}

Immediate Recall/Recognition. At the end of each training session participants were asked to free recall, or recognize if they were unable to recall, the target person. Table 14a and $14 \mathrm{~b}$ show the results for each participant. During the first week of training, most participants were unable to free recall the target person. Only two successful free recall responses were observed in the first week of training, S3 on day 3 and S5 on day 5 . In second week of training, several participants were able to free recall the target person at the end of at least one session. S3 and S5 consistently recalled the target over all three days. S4 recalled the target on two of the days and S2 was successful on only one day. S6 and S7, however, were never able to free recall the target correctly. The finding that most participants were never able to consistently recall the trained target person only moments after the completion of the session is noteworthy. This is especially interesting in that the participants had been trained with the target on as many as 49 trials. This finding is consistent with the secondary memory impairment often found in older adults with probable AD.

When participants were unable to free recall the target, all nine pictures were presented again for the recognition task. Participants were quite successful at picking out the target from the other eight pictures. S2, S3 and S5 were able to recognize the target in every session. S4, S6 and S7 each had two sessions when they were unable to recognize the target. The fact that all participants were able to recognize the target, the majority of 
Table 14a: Summary of Immediate Recall Task for Alternate Day S-R Schedule

\begin{tabular}{cccc} 
& \multicolumn{2}{c}{ Participants } & S6 \\
\hline $\begin{array}{l}\text { Measure } \\
\text { Recall/Recognition }\end{array}$ & S5 & \\
Day 3 & $0 / 1$ & & $0 / 0$ \\
Day 4 & $0 / 1$ & $0 / 1$ & $0 / 1$ \\
Day 5 & $0 / 0$ & $1 /-$ & $0 / 1$ \\
Day 6 & $0 / 0$ & $1 /-$ & $0 / 1$ \\
Day 7 & $1 /-$ & $1 /-$ & $0 / 0$ \\
Day 8 & $1 /-$ & $1 /-$ & $0 / 1$ \\
& & & \\
\hline
\end{tabular}

Table 14b: Summary of Immediate Recall Task for Consecutive Day S-R Schedule

\begin{tabular}{lcc}
\multicolumn{3}{c}{ Participants } \\
S2 & S3 & S7
\end{tabular}

\begin{tabular}{|c|c|c|c|}
\hline $\begin{array}{l}\text { Measure } \\
\text { Recall/Recogn }\end{array}$ & & & \\
\hline Day 3 & $0 / 1$ & $1 /-$ & $0 / 0$ \\
\hline Day 4 & $0 / 1$ & $0 / 1$ & $0 / 1$ \\
\hline Day 5 & $0 / 1$ & $0 / 1$ & $0 / 1$ \\
\hline Day 6 & $1 /-$ & $1 /-$ & $0 / 1$ \\
\hline Day 7 & $0 / 1$ & $1 /-$ & $0 / 0$ \\
\hline Day 8 & $0 / 1$ & $1 /-$ & $0 / 1$ \\
\hline
\end{tabular}

of 1 indicates Ss could name or recognize the target person. 
the time, suggests that they all had knowledge of the target person but may have been unable to access that knowledge during the free recall task. The re-presentation of the stimulus was enough to prompt successful recognition of the target. These findings are consistent with the results of the SPT data, which found participants did more poorly on free recall in comparison with cued recall (see Table 8).

Delayed Recall. Each participant's performance on the delayed recall task can be found in Table $15 \mathrm{a}$ and $15 \mathrm{~b}$. As can be seen, the target was successfully recalled only three times, on day 7 by S3 and on day 8 by S3 and S5. The other participants failed to successfully recall the target in the delayed recall task on all five days. These results are similar to the findings of the immediate recall task in that participants are unable to remember the target when tested only with free recall. These findings replicate the results of the delayed recall task in previous spaced-retrieval studies utilizing this same paradigm (see Cherry \& Simmons-D’Gerolamo, 1999, Cherry et al., 1999).

Final Recall/Recognition. Table $16 \mathrm{a}$ and $16 \mathrm{~b}$ contain participants' scores on the final delayed recall task. Only two participants were able to free recall the target person, S3 (days 6 and 9) and S5 (day 9). However, all other participants were able to recognize the target when presented with the other eight pictures. All participants correctly recognized the target on both day 6 and day 9, except for S6, who only recognized the target on day 9. These data lend more evidence to the idea that participants retained the target information trained with spaced-retrieval but are unable to free recall that information. These findings replicate those of the immediate recall task. Participants, again, demonstrate their ability to recognize the target person but seem unable to access that knowledge during free recall. The results of the final recall/recognition task also complement the SPT data in that participants were more 
Table 15a: Summary of Delayed Recall Task for Alternate Day S-R Schedule

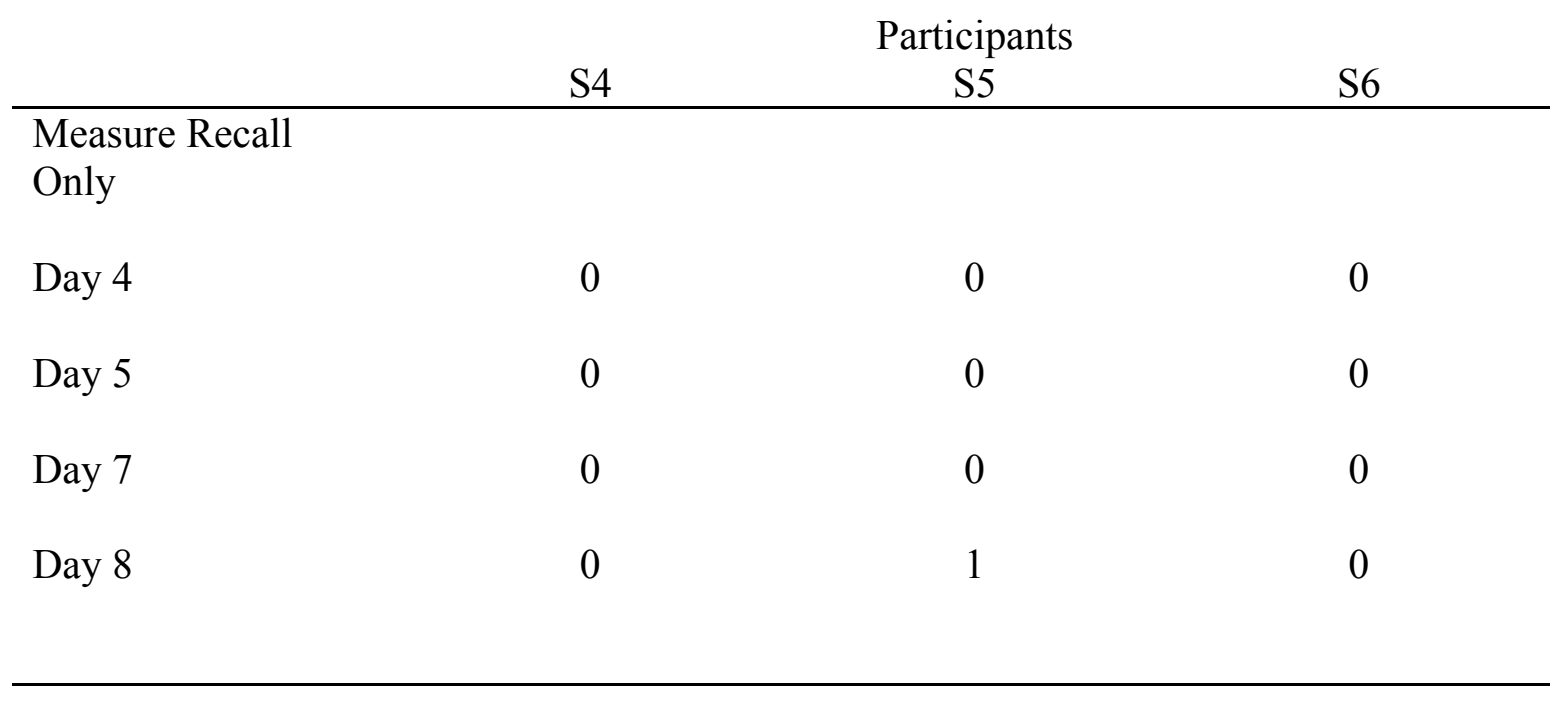

Table 15b: Summary of Delayed Recall Task for Consecutive Day S-R Schedule

\begin{tabular}{lccc} 
& \multicolumn{2}{c}{ Participants } & S7 \\
\hline $\begin{array}{l}\text { Measure Recall } \\
\text { Only }\end{array}$ & S2 3 & \\
Day 4 & 0 & & 0 \\
Day 5 & 0 & 0 & 0 \\
Day 7 & 0 & 1 & 0 \\
Day 8 & 0 & 1 & 0
\end{tabular}

Note. Scores of 0 indicate the Ss did not name the target person, whereas, a score of 1 indicates the Ss did name the target person. 
Table 16a: Summary of Final Delayed Recall Task for Alternate Day S-R Schedule

Participants

S4 S5 $\quad$ S6

Measure

Recall/Recognition
Day 6
$0 / 1$
$0 / 1$
$0 / 0$

Day 9

$0 / 1$

$1 /-$

$0 / 1$

Table 16b: Summary of Final Delayed Recall Task for Consecutive Day S-R $\underline{\text { Schedule }}$

Participants

$\begin{array}{lll}\text { S2 } & \text { S3 } & \text { S7 }\end{array}$

Measure

Recall/Recognition

$\begin{array}{cccc}\text { Day } 6 & 0 / 1 & 1 /- & 0 / 1 \\ \text { Day } 9 & 0 / 1 & 1 /- & 0 / 1\end{array}$

Note. Scores of 0 indicate Ss could not name/recognize the target person, whereas, a score of 1 indicates Ss could name/recognize the target person. 
likely to remember the participant performed action when cued with the actual object (see Table 8).

\section{Final Face Recognition Task}

On the last day of the study (day 9), participants were presented with 18 photographs, 9 were the stimuli from the spaced-retrieval training and 9 were distracter items. Participants were asked to identify the pictures they had seen before. Table 17 contains the results of performance on this task. Overall, participants were able to correctly identify more stimuli photographs (hits) than falsely identifying new items (false alarms). Participants also failed to identify old items (misses) fewer times than they correctly rejected new items (correct responses). All six participants were able to select the target picture as a photograph they had seen before. These findings provide evidence that mere exposure to the photographs during spaced-retrieval training is not sufficient for maintaining recall and recognition of the items. Spaced-retrieval training on the item appears necessary for success in recalling or recognizing the item.

\section{Training Schedule Findings}

Overall, the spaced-retrieval training schedule appears to make no difference on any of the tasks. There is no emerging pattern from the spaced-retrieval training data (see Table 11) to suggest that one schedule is more beneficial than the other. For instance, of the three participants who were able to identify the target correctly on the transfer task, two of them (S2 and S7) were on the consecutive day schedule (i.e. T, W, Th). On first observation, it may appear that the task for this group may have been easier due to the participants having just received training the previous day. However, recall that there is a weekend delay between training sessions and the transfer task. The every day schedule actually had a 
Table 17: Summary of Final Face Recognition Task

Participants

\begin{tabular}{|c|c|c|c|c|c|c|}
\hline \multirow[b]{2}{*}{ Old Items } & $\mathrm{S} 2$ & $\mathrm{~S} 3$ & $\mathrm{~S} 4$ & S5 & S6 & S7 \\
\hline & & & & & & \\
\hline Hits & 5 & 5 & 7 & 4 & 5 & 6 \\
\hline Misses & 4 & 4 & 2 & 5 & 4 & 3 \\
\hline \multicolumn{7}{|l|}{ New Items } \\
\hline $\begin{array}{l}\text { False } \\
\text { alarms }\end{array}$ & 2 & 3 & 4 & 1 & 1 & 0 \\
\hline $\begin{array}{l}\text { Correct } \\
\text { responses }\end{array}$ & 7 & 6 & 5 & 8 & 8 & 9 \\
\hline
\end{tabular}

Note. Entries are based on a total of 9 facial pictures used in SR training ("old items") and 9 distracter faces ("new items").

longer delay in comparison to the alternate day schedule, four days in comparison to 2 days, so the task for these participants could be viewed as more difficult. When comparing the two groups on the transfer task they are comparable in that two participants in each group showed improvement and one participant in each group showed no improvement. The scores on the immediate recall task (see Table 14a and 14b), the delayed recall task (see Table 15a and 15b) and the final delayed recall task (see Table 16a and 16b) are almost identical between the groups. 


\section{GENERAL DISCUSSION}

The results of this study further confirm that the spaced-retrieval technique is a viable intervention for facilitating recall in older adults with probable AD. In accordance with our first aim of the research, the present results indicated that the spaced-retrieval technique could be adapted to promote the learning and recall of name-face associations in persons with probable AD (Cherry et al., 1999). These findings provide preliminary evidence that the name-face association trained via spaced-retrieval does transfer to an actual target person, in accordance with the second aim of the study. In addition, the results provide evidence that the schedule of spaced-retrieval training can be modified, from every other day to consecutive days, with no appreciable difference in performance. These findings are discussed in more detail next.

\section{Spaced-Retrieval Effects}

The first goal of the present study was to determine whether the spaced-retrieval training used by Cherry et al. (1999) could be adapted to help cognitively impaired older adults learn and retain name-face associations. Recent research by Cherry and SimmonsD'Gerolamo (1999) found that the spaced-retrieval paradigm is useful in facilitating learning and retention in persons with AD. We used an adapted version of Cherry et al.'s (1999) method and procedures to train the name-face association. Our findings provide evidence that spaced-retrieval training can be adapted to facilitate the learning and retention of nameface associations. This is an exciting finding, having applied implications for memory remediation in the daily lives of $\mathrm{AD}$ patients. That is, our findings imply that caregivers could use the spaced-retrieval techniques to help AD patients remember names of family members. 
Our results also provide evidence for the maintenance of spaced-retrieval training effects over time. We included six training sessions across a two-week period. As expected, participants became more proficient at the spaced-retrieval training task over sessions, as reflected in longer retention intervals in the later sessions compared to early sessions. For example, S4's longest retention interval in session 1 and 2 was 10 seconds and 20 seconds, in comparison to session 5 and 6 when she maintained the association for 120 seconds and 180 seconds (see Table 11). Another expected finding was that the number of failures for each participant decreased across sessions. For example, S7 had 15 failures in session 1, 13 failures in session 4, and only 1 failure in session 6 (see Table 11). These findings provide additional evidence that, over time, participants benefited from prior training sessions.

In the current study, the photographs used to train the name-face association were of persons that the participants had no previous relationship with. Future research could incorporate pictures of persons who are meaningful to the participants, such as family members, friends and caregivers. Incorporating these types of persons may provide a more direct benefit of the training to the participants, a possible direction for further research in this paradigm.

\section{Transferring Spaced-Retrieval Training Association to a Live Person}

The findings of the present study provide initial evidence that spaced-retrieval training of name-face associations can transfer to a live person, the second goal of the study. The results are promising in that half of the participants $(\mathrm{S} 2, \mathrm{~S} 4, \mathrm{~S} 7)$ were able to identify the live person by the correct name at the end of the second week of training. The others (S3, S5, S6) were able to identify the live target's picture from among the distracters. In 
addition, S5 was able to call the target by the correct name after recognizing the target picture. These findings are exciting in that they provide evidence of AD patients being able to apply name-face associations trained via spaced-retrieval to an actual person. Although not all of the participants were able to call the target person by name, in general, participants showed improvement in the task across the two weeks of training. Future research could extend the training by an additional week to allow participants to improve in their recall of the target person. Future studies could also explore training more than one association for the target photograph in each session. For example, in addition to the face-name association also train the association of the target's occupation (i.e. this is Susan and she is a nurse).

\section{Spaced-Retrieval Training Schedule}

Our study found no difference in performance for participants on a consecutive day schedule (i.e. $\mathrm{T}, \mathrm{W}, \mathrm{Th})$, in comparison to participants on an alternate day schedule (M, W, F). This finding is encouraging because when working with special populations, scheduling multiple training sessions, such as those used in the spaced-retrieval paradigm, can prove to be a challenge. Future studies could seek to replicate this finding and explore the influences of additional schedules on memory performance.

\section{Informal Observations}

In this section, informal observations of each participant are discussed to provide additional insight into this sample and suggest directions for further research. As a general statement, AD patients have "good days" and "bad days". The behavior and mood of persons with probable AD can be unpredictable and can change in a moment. This section is designed to provide insight into how such behavioral anomalies may have influenced some of the research findings. 
S2 was a very talkative person, so it was very difficult for her to stay on task. She told lots of stories from her childhood and became very involved in these stories. In the first two training sessions, she would continue talking even when the buzzer went off and not even acknowledge the buzzer. S2 would often talk to the photographs and act as if she knew them. When the buzzer went off she would ask, "Are you looking for your daughter, Susan?" and then hand me the target picture. Although she focused on the photographs more than other participants, her performance was not affected. As one can tell from S2's performance on the spaced-retrieval task (Table 11), she had only 1 partially correct failed trial in session 1 and in session 2, which may be the result of her in depth story telling and her not responding to the buzzer. Also, in session 6, S2 reached her longest duration of 360 seconds, although she had 28 total trials. This pattern may be due to her story telling. The participant was involved in telling a story so the experimenter extended the session for an additional trial. Although S2's performance may have been inhibited in the early sessions due to her in depth storytelling, the benefit of spaced-retrieval can still be observed across training sessions. Her performance illustrates how spaced-retrieval works with minimal effort put forth by the participant and demonstrates that even a distracted participant, such as S2, can benefit from training with the paradigm.

S3 was a very interesting participant. Although she did not score the highest on the individual differences measures (see Table 8), she performed significantly better than all participants on the first session of spaced-retrieval training. Overall, S3 performed well throughout the sessions, so it is somewhat surprising to observe her decline on the spacedretrieval trials in session 6 and on the second transfer task. Her performance on these days is interesting due to her success on other tasks those days such as the delayed recall task (see 
Table 15b) and the prospective nametag task (see Table 10). S3 had the highest score on the nametag task (17 out of 36), on which four days she remembered on the first cue to turn in her nametag. The decline in performance in the last two sessions illustrates the variability that can occur in working with this population.

S4 was another talkative lady. She had difficulty remembering the task. Unlike S2 who did not acknowledge the buzzer, S4 would acknowledge the buzzer much of time but not recall what she was supposed to do. She had the largest number of failed trials in the first two sessions. In session 2 alone she required 49 total trials. However, she showed the most consistent improvement of all the participants. She was also able to identify the target person by name.

S5 was a very sweet, soft-spoken lady. She talked a great deal about missing her home in Mississippi. She appeared to catch on to the task easily, as she experienced very few failed trials after session 1, and by session 6 experienced no failed trials. S5's performance in session 6 might lead one to expect she would perform well on the second live person transfer task. She did do well in that she picked the target picture and correctly identified the target name, however, she could not free recall the target's name when asked to do so. When asked the target name, S5 responded, Francis, in fact, she stated the name Francis in both the first and second transfer tasks. Francis was not the name of any of the distracter photographs so perhaps the participant knew someone named Francis that looked like the target.

S6 was the only gentleman in this study. He was also the lowest functioning of the participants (i.e., the lowest MMSE score, see Table 8). He was quiet in comparison to other participants but would respond to questions. S6 had difficulty catching on to the task. 
After three days of training he was still only able to reach a retention interval of 10 seconds (see Table 11). However, by Sessions 5 and 6 he was able to retain the association for 60 seconds. This is remarkable considering his functioning level. S6's trials within sessions looked a bit different from other participants. Fatigue appeared to be a factor for him as he showed sharp drops in his retention after achieving some success. For example, his last 5 trials in session 6 were all failures in comparison to most other participants who rebounded back to a successful trial after only one, or at the most two, failed trials. His overall improvement is encouraging in that spaced-retrieval may prove be a viable intervention for more cognitively impaired individuals such as S6. Further research utilizing spacedretrieval as an intervention with more cognitively impaired AD patients (i.e. MMSE scores of 4-8) is necessary before firm conclusions could be warranted.

S7 was the highest functioning of all the participants (see Table 8). Although not reflected in her individual difference scores, S7 often asked the same questions and told the same stories. S7 is interesting in that her improvement tended to be more gradual. For example, her longest duration for the first three sessions was 60 seconds. Sessions 4 and 5 both showed a longest duration of 90 seconds and then in the last session she jumped to an interval of 360 seconds. Her performance illustrates that the same benefit of spacedretrieval can be achieved, even though participants may perform at a more gradual pace, requiring more sessions to show an improvement.

Overall, our findings complement the previous body of research on the use of spacedretrieval as an intervention with older adults with probable AD. The results replicate the work of Cherry et al. (1999) in that spaced-retrieval enhanced the retention of the target association, within and across sessions, for all participants. Our results provide additional 
evidence of the efficacy and adaptability of this paradigm. The finding that the name-face association transferred to a live person is exciting in itself, but also provides practical implications for future research. Camp and Schaller (1989) successfully trained an AD patient via spaced-retrieval to remember a caregiver's name, however, the caregiver was present throughout all trials and sessions. The evidence that the name-face association can be trained through the use of photographs, without the target person being physically present, overcomes the hurdle that the training may require too much involvement from the target person to actually implement into everyday life.

In closing, the results of this study are promising. The implications for both caregivers and the AD participants themselves are noteworthy. From an applied perspective, older adults with probable $\mathrm{AD}$ could be taught to recall important persons in their life by name, thus increasing a sense of mastery and increased overall self-esteem. Caregivers and family members would experience less frustration with older adults with probable AD as a connection could be maintained through the use of the significant person's name. Ideally, the technique could be taught to both caregivers and family members for application in the home environment. The results here warrant exploration of the efficacy of this technique with other dementia populations such as persons suffering with multi-infarct dementia. 


\section{REFERENCES}

Abrahams, J. P., \& Camp, C. J. (1993). Maintenance and generalization of object naming training in anomia associate with degenerative dementia. Clinical Gerontologist, 12(3), 57-71.

Alessi, C. A., Schnelle, J. F., MacRae, P. G., Ouslander, J. G., Al-Samarrai, N., Simmons, S. F., \& Traub, S. (1995). Does physical activity improve sleep in impaired nursing home residents? Journal of the American Geriatrics Society, 43(10), 1098-1102.

Alexopoulos, G. S. (1996). The treatment of depressed demented patients. The Journal of Clinical Psychiatry, 57 (suppl. 13), 14-20.

Alexopoulos, P. (1994). Management of sexually disinhibited behaviour by a dementia patient. Australian Journal on Ageing, 13(3), 119.

Alzheimer's Association (1998). Alzheimer's disease statistics. [Brochure]

American Psychiatric Association. (1994). Diagnostic and statistical manual of mental disorders (4th ed.). Washington, DC: Author.

Aronson, M. K., Post, D. C., \& Guastadisegni, P. (1993). Dementia, agitation, and care in the nursing home. Journal of the American Geriatrics Society, 41(5), 507-512.

Azuma, T., \& Bayles, K. A. (1997). Memory impairments underlying language difficulties in dementia. Topics in Language Disorders, 18(1), 58-71.

Baddeley, A. (1996). Exploring the central executive. Quarterly Journal of Experimental Psychology, 49A(1), 5-28.

Baddeley, A. D., Baddeley, H. A., Bucks, R. S., \& Wilcock, G. K. (2001). Attentional control in Alzheimer's disease. Brain, 124, 4192-1508.

Baltes, P. B., \& Mayer, K. U. (1999). The Berlin Aging Study: Aging from 70 to 100. New York, NY: Cambridge University Press.

Bird, M., Alexopoulos, P., \& Adamowicz, J. (1995). Success and failure in five case studies: Use of cued recall to ameliorate behaviour problems in senile dementia. International Journal of Geriatric Psychiatry, 10, 305-311.

Bird, M., \& Kinsella, G. (1996). Long-term cued recall of tasks in senile dementia. Psychology and Aging, 11(1), 45-56. 
Bliwise, D. L., Hughes, M., McMahon, P. M., \& Kutner, N. (1995). Observed sleep/wakefulness and severity of dementia in an Alzheimer's disease special care unit. Journal of Gerontology: Medical Sciences, 50A(6), M303-M306.

Camp, C. J., Bird, M. J., \& Cherry, K. E. (2000). Retrieval strategies as a rehabilitation aid for cognitive loss in pathological aging. In R. D. Hill, L. Backman, \& A. Stigsdotter Neely (Eds.), Cognitive rehabilitation in old age (pp. 224-248). New York, NY: Oxford University Press.

Camp, C. J., Foss, J. W., O’Hanlon, A. M., \& Stevens, A. B. (1996). Memory Interventions for persons with dementia. Applied Cognitive Psychology, 10, 193-210.

Camp, C. J., \& Schaller, J. (1989). Epilogue: Spaced-retrieval memory training in an adult day-care center. Educational Gerontology, 15, 641-648.

Camp, C. J., \& Stevens, A. B. (1990). Spaced-retrieval: A memory intervention for dementia of the Alzheimer's type (DAT). Clincial Gerontologist, 10(1), 58-61.

Cherry, K. E., Moore, G., \& Kelley, S. (1996). Predictors of participation in group activities in nursing home residents. Unpublished Manuscript.

Cherry, K. E., \& Park, D. C. (1993). Individual difference and contextual variables influence spatial memory in younger and older adults. Psychology and Aging, $\underline{8}(4), 517-526$.

Cherry, K. E., \& Plauche, M. (1996). Memory impairment in Alzheimer's disease: Findings, interventions, and implications. Journal of Clinical Geropsychology, 2(4), 263-296.

Cherry, K. E., Simmons, S. S., \& Camp, C. J. (1999). Spaced-retrieval enhances memory in older adults with probable Alzheimer's disease. Journal of Clinical Geropsychology, 5(3), 159-175.

Cherry, K. E., \& Simmons-D'Gerolamo (1999). Effects of a target object orientation task on recall in older adults with probable Alzheimer's disease. Clinical Gerontologist, 20(4), 39-63.

Cohen-Mansfield, J., Reisberg, B., Bonnema, J., Berg, L., Dastoor, D.P., Pfeffer, R.I., \& Cohen, G.D. (1996). Staging methods for the assessment of dementia: Perspectives. Journal of Clinical Psychiatry, 57(5), 190-197. 
Cummings, J. L., Mega, M., Gray, K., Rosenberg-Thompson S., Carusi, D. A., \& Gornbein, J. (1994). The Neuropsychiatric Inventory: Comprehensive assessment of psychopathology in dementia. Neurology, 44, 2308-2314.

Doraiswamy, P. M., Steffens, D. C., Pitchumoni, S., \& Tabrizi, S. (1998). Early recognition of Alzheimer's disease: What is consensual? What is controversial? What is Practical? The Journal of Clinical Psychiatry, 59 (suppl. 13), 6-18.

Epping, F.J., \& Poisal, J.A. (1996). Mental Health of Medicare Beneficiaries: 1995. Health Care Financing Review, 81(3), p.207-210.

Ernst, R. L., \& Hay, J. W. (1994). The US economic and social costs of Alzheimer's disease revisited. American Journal of Public Health, 84, 1261-1264.

Fama, R., Sullivan, E. V., Shear, P. K., Stein, M., Yesavage, J.A., Tinklenberg, J. R., \& Pfefferbaum, A. (2000). Extent, pattern, and correlates of remote memory impairment in Alzheimer's disease and Parkinson's disease. Neuropsychology, 14(2), 265-276.

Folstein, M.F., Folstein, S.E., \& McHugh, P.R. (1975). "Mini-Mental State”: A practical method for grading the cognitive state of patients for the clinician. Journal of Psychiatric Research, 12, 189-198.

Gruetzner, H. (1992). Alzheimer's a caregiver's guide and sourcebook. New York: John Wiley \& Sons, Inc.

Gutterman, E. M., Markowitz, J. S., Lewis, B., \& Fillit, H. (1999). Cost of Alzheimer's disease and related dementia in managed-medicare. The Journal of the American Geriatric Society, 47(9), 1065-1071.

Henderson, C. W. (1998). Dementia experts sound alarm on Alzheimer's scourge. World Disease Weekly Plus [On line], Oct. 19, 1998. Available: Infotrac.galegrounp article A53109590.

Hendrie, H. C. (1997). Epidemiology of Alzheimer's disease. Geriatrics, 52(9), p.s4-s9.

Hill, R. D., Yesavage, J. A., Sheikh, J., \& Friedman, L. (1989). Mental status as a predictor of response to memory training in older adults. Educational Gerontology, $\underline{15}, 633-639$.

Holden, C. (1987). OTA cites financial disaster of Alzheimer's. Science, 236, p.253. 
Huff, J. F. (1988). The disorder of naming in Alzheimer's disease. In L. L. Light, and D. M. Burke (Eds.), Language, memory, and aging (pp. 209-219). Cambridge: Cambridge University Press.

Jarvik, L. F. (1980). Diagnosis of dementia in the elderly: A 1980 perspective. Annual Review of Gerontology and Geriatrics.

Jastak, J., \& Jastak, S. (1965). Short forms of the WAIS vocabulary subtest. Journal of Clinical Psychology, 20, 167-199.

Kaplan, E., Goodglass, H., \& Weintrub, S. (1983). Boston Naming Test $\left(2^{\text {nd }}\right.$ ed $)$. Philadelphia: Lea \& Farbiger.

Landauer, T.K., \& Bjork, R.A. (1978). Optimum rehearsal patterns and name learning. In M.M. Gruneberg, P. E. Morris, \& R. N. Sykes (Eds.), Practical aspects of memory (pp.625-632). London: Academic Press.

Lopez, O. L., Wisniewski, S., Hamilton, R. L., Becker, J. T., Kaufer, D. I., \& DeKosky, S. T. (2000). Predictors of progression in patients with AD and Lewy bodies. Neurology, 54, 1774-1779.

Lyketsos, C. G., Steinberg, M., Tschanz, J. T., Norton, M. C., Steffens, D. C., \& Breitner, J. C. (2000). Mental and behavioral disturbances in dementia: Findings from the cache county study on memory in aging. American Journal of Psychiatry, 157(5), 708-714.

Mace, N.L., \& Rabins, P.V. (1991). The 36-Hour Day. New York, NY: Time Warner.

McKitrick, L. A., \& Camp, C. J. (1993). Relearning the names of things: The spacedretrieval intervention implemented by a caregiver. Clinical Gerontologist, 14(2), 6062.

McKitrick, L.A., Camp, C. J., \& Black, F.W. (1992). Prospective Memory Intervention in Alzheimer's Disease. Journal of Gerontology, 47(5), 337-343.

McShane, R., Gedling, K. Keene, J., Fairburn, C., Jacoby, R., \& Hope, T. (1998). Getting lost in dementia: A longitudinal study of a behavioral symptom. International Psychogeriatrics, 10(3), 253-260.

Meguro, K., Ueda, M., Kobayashi, I., Yamaguchi, S., Yamazaki, H., Oikawa, Y., Kikuchi, Y., \& Saski, H. (1995). Sleep disturbance in Elderly Patients with cognitive impairment, deceased daily activity and periventricular white matter lesions. Sleep, 18(2), 109-114. 
National Institute of Aging (1999). Progress Report on Alzheimer's Disease. (DHHS Publication No. 99-4664). Washington, D.C.: U.S. Government Printing Office.

Nebes R. D. (1993). Cognitive dysfunction in Alzheimer's disease. In F. I. M. Craik, and T. A. Salthouse (Eds.), The handbook of aging and cognition (pp. 373-446). Hillsdale, NJ: Erlbaum.

Neistein, S., \& Siegal, A. P. (1996). Agitation, wandering, pacing, restlessness, and repetitive mannerisms. International Psychogeriatrics, 8(suppl. 3), 399-402.

Ory, M.G., Hoffman, R. R., Yee, J. L., Tennstedt, S., \& Schulz, R. (1999). Prevalence and impact of caregiving: A detailed comparison between dementia and non dementia caregivers. The Gerontologist, 39 (2), 177-185.

Parasuraman, R., \& Nestor, P. G. (1993). Preserved cognitive operation in early Alzheimer's disease. In J. Cerella, J. Rybash, W. Hoyer, and M. L. Commons (Eds.), Adult information processing; Limits on loss (pp. 77-111). New York: Academic Press.

Peskind, E. R. (1996). Neurobiology of Alzheimer's disease. The Journal of Clinical Psychiatry, 57 (suppl. 13), 5-8.

Raskind, M. A., \& Peskind, E. R. (1992). Alzheimer's disease and other dementing disorders. In J. E. Birren, R. B. Sloane, and G. D. Cohen (Eds.), Handbook of mental health and aging (2nd ed., pp. 447-513). New York: Academic Press.

Reisberg, B., Ferris, S. H, deLeon, M. J., Crook, T., \& Haynes, N. (1987). Senile Dementia of the Alzheimer's Type. In M. Bergener (Eds.), Psychogeriatrics: An international handbook (pp. 306-334). New York: Springer Publishing Company.

Richards, M., \& Stern, Y. (1992). Cognitive studies of Alzheimer's disease. In D. Stein, and J. Young (Eds.), Cognitive science and clinical disorders, San Diego, CA: Academic Press.

Sheikh, J. L., \& Yesavage, J. A. (1986). Geriatric Depression Scale (GDS): Recent evidence and development of a shorter version. In T. L. Brink (Ed.), Clinical gerontology (pp. 165-173). New York: Haworth Press.

Shiffrin, R. M., \& Schneider, W. (1977). Controlled and automatic human information processing: II. Perceptual learning, automatic attending, and a general theory. Psychological Review, 84, 127-190.

U.S. Bureau of the Census (1996). Current Population Reports, special studies, $65+$ in the U.S. [On-line]. P.23-190. Available: www.census.org. 
Wechsler, D. (1955). Wechsler Adult Intelligence Scale (7th ed.). New York: Psychological Corporation.

Wilms, H. U., Kanowski, S., \& Baltes, M. M. (2000). Limitations in activities of daily living: Towards a better understanding of subthreshold mental disorders in old age. Comprehensive Psychiatry, 41(2)(suppl. 1), 19-25.

Yang, C., Hwang, J., Tsai, S., \& Liu, C. (1999). Wandering and associated factors in psychiatric inpatients with dementia of Alzheimer's type in Taiwan: Clinical implications for management. Journal of Nervous and Mental Disease, 187(11), 695-697.

Yesavage, J. A. (1982). Degree of dementia and improvement with memory training. Clinical Gerontologist, 1(2), 77-81.

Yesavage, J. A., Brooks, J. O., Taylor, \& Tinklenberg, J. (1993). Development of aphasia, apraxia, and agnosia and decline in Alzheimer's disease. American Journal of Psychiatry, 150(5), 742-747. 


\section{VITA}

Karri S. Hawley is currently in a doctoral program in developmental psychology at Louisiana State University. Mrs. Hawley's areas of interest include cognitive aging and more specifically Alzheimer's disease. Karri obtained a Bachelor of Science degree in psychology from Georgia Southern University in 1993. She went on to complete a Master of Education degree in counseling at The University of North Florida in 1996. She anticipates obtaining the degree of Doctor of Philosophy in psychology in the spring of 2004. 